\title{
FOREX Risk: Measurement and Evaluation using Value-at-Risk
}

\author{
By
}

Don Bredin*

University College Dublin

and

\section{Stuart Hyde}

\section{University of Manchester}

Research on this paper was carried out while Don Bredin was an economist in the Central Bank of Ireland. The views expressed in this paper are the personal responsibility of the authors and are not necessarily held either by the Central Bank of Ireland or by the ESCB. The authors would like to thank John Frain and Richard Harris for helpful comments. All errors and omissions are the authors'. Comments and criticisms are welcome.

\footnotetext{
* Corresponding Author: Don Bredin, Department of Banking \& Finance, Graduate School of Business, University College Dublin, Blackrock, Dublin.

Tel.(353-1) 716 8833. Fax: (353-1) 283 5482. email: don.bredin@ucd.ie
} 


\begin{abstract}
In this paper we measure and evaluate the performance of a number of Value-at-Risk (VaR) methods using a portfolio which is based on the foreign exchange exposure of a small open economy (Ireland) among its key trading partners. A number of recent studies have compared the various methods of measuring risk, however, we are primarily concerned with the evaluation of these methods. The sample period highlights the changing nature of Ireland's exposure to risk over the past decade in the run-up to EMU. The novel aspect of our analysis is that we measure the portfolio risk faced by firms (e.g. banks, exporters) using new risk management techniques. Our results will offer an indication as to the level of accuracy of the various approach's and discuss the issues of models ensuring statistical accuracy or more conservative leanings. The approach we will adopt is based on the Value-at-Risk models. We investigate the two central VaR modelling methodologies, parametric and non-parametric analysis. Results based on recently developed evaluation techniques would appear to suggest that the Orthogonal GARCH model is the most accurate methodology while the exponentially weighted moving average (EWMA) specification is the more conservative approach.
\end{abstract}




\section{0 : Introduction}

Over the past decade the growth of trading activity in financial markets, numerous instances of financial instability, and a number of widely publicised losses on banks' trading books have resulted in a re-analysis of the risks faced, and how they are measured. The most widely advocated approach to have emerged to measure market risk is that of Value-at-Risk (VaR). VaR is an estimate of the largest loss that a portfolio is likely to suffer, i.e. the potential loss faced by the firm. This paper outlines the alternative approaches to measuring VaR that exist. In the context of assessing Ireland's foreign exchange exposure among its key trading partners, we discuss the standard variance-covariance approach, an Exponentially Weighted Average technique, an Orthogonal Generalised Autoregressive Conditional Heteroscedasticity specification and the historical simulation methodology. The Irish context is of particular interest since as a small open economy not only does it have a high reliance on trade, in fact, over the period examined, trade accounted for over 120\% of GDP, but also it has been affected by the move towards EMU.

Under the 1997 Amendment to the Basle Accord and the second Capital Adequacy Directive (CAD) adopted by the European Union, banks are able to seek approval for the adoption of their own in-house VaR models in order to calculate the minimum regulatory required capital to cover their market risks ${ }^{\square}$. Given that banks are permitted to develop differing VaR models, it is necessary for supervisory bodies to be able to assess the relative performance of these alternative models. This issue is highlighted by Hendricks and Hirtle (1997, pp. 8-9):

"The actual benefits to be derived from the VaR estimates depend crucially on the quality and accuracy of the models on which the estimates are based. To the extent that these models are inaccurate and misstate the banks' true risk exposures, then the quality of the information derived from any public disclosure will be degraded. More important, inaccurate VaR models or models that do not produce consistent estimates over time will undercut the main benefit of a models-based

\footnotetext{
${ }^{1}$ Likewise regulatory authorities in the US and Australia have adopted the market risk amendment to the Basle Capital Accord.
} 
capital requirement: the closer tie between capital requirements and true risk exposures. Thus, assessment of the accuracy of these models is a key concern and challenge for supervisors."

Engel and Gizycki (1999) identify three banners under which such decisions can be made. These are conservatism, accuracy and efficiency. Supervisory bodies are not only concerned with the accuracy of potential models but also the level of conservatism regarding the estimated measure of risk. A conservative model can be defined as one that produces consistently high estimates of risk relative to other models. In addition, firms are concerned with model efficiency. They wish to adopt VaR models that will both satisfy capital adequacy requirements and thus be sufficiently conservative to please the supervisors and minimise the level of capital reserves that must be held. Furthermore, it is of interest to firms to be able to evaluate the performance of contesting models prior to adoption of any one model. It will be expensive in terms of both time and money for a firm to change, once any one model has been adopted as best practice within the firm. Over recent years the range of techniques available to risk managers has increased vastly, therefore the decision of which methodology to adopt is no longer straightforward, the many alternative approaches should all be considered.

The sample studied (1990-1998) represents a period where the foreign exchange rate risk represented an important part risk. ${ }^{6}$ This research represents the first part of a comprehensive study which will analyse the risks faced by firms/banks in the Irish market. The study focuses on the foreign exchange market, which was certainly faced with a high degree of volatility over the early part of the

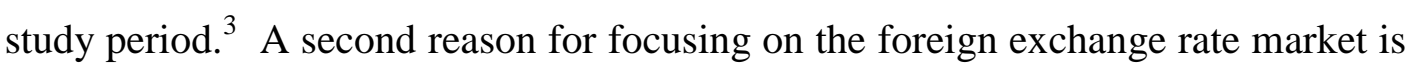
that we have a linear relationship and so eases comparison of the various models. The importance of the differing techniques has been the topic of a number of recent finance papers, however, this is the first known study to explicitly consider the

\footnotetext{
2 During the 1990's derivative trading grew dramatically, the bulk of which, in the case of Ireland, was in the forward foreign exchange area, (see Browne, Fell and Hughes, 1994).

${ }^{3}$ Although the adoption of the euro will reduce substantially the degree of foreign exchange risk exposure faced by banks and exporters, there are still risks associated with important trade partners outside the euro, i.e. US and the UK.
} 
problem in the context of a small open economy and the impact of impending monetary union. 7

The paper adopts six different models based on those mentioned earlier to generate $\mathrm{VaR}$ forecasts using four different holding periods. The accuracy of these forecasts are then analysed using three differing evaluation processes. Firstly, we adopt two measures of relative size and variability developed by Hendricks (1996). Secondly, we then use interval forecasts proposed by Christoffersen (1998). The framework is independent of the model process generating the $\mathrm{VaR}$ forecasts and captures whether a particular model exhibits correct conditional coverage. As such the VaR forecasts should be small in periods exhibiting low volatility and larger in more volatile periods. Occasions when the loss actually exceeds the VaR forecast, known as a failure or exception, should therefore be spread across the sample and not appear in clusters. A model which does not capture the volatility dynamics of the underlying return distribution will exhibit a clustering of exceptions but may still exhibit correct unconditional coverage. Finally we adopt the loss function approach of Lopez (1999). The functions are defined to produce higher values when exceptions occur. In this paper we adopt two functions, a basic binary loss function which in a sense equivalent to the Christoffersen test of correct unconditional coverage, and a quadratic loss function which takes into account the magnitude of the exception. We find that of the models considered the Exponentially Weighted Moving Average (EWMA) model with a weighting of 0.94 performs best according to the evaluation statistics.

\section{0: Methodology}

In this paper we analyse different aspects of the VaR methodology using a number of foreign exchange portfolios. The VaR measure provides an estimate of the potential loss on a portfolio that would occur given relatively large adverse price movements. Assuming that over a given time period, the composition of the portfolio remains unchanged, the VaR statistic is a one-sided confidence interval on portfolio losses, such that:

\footnotetext{
${ }^{4}$ See, inter alia, Engel and Gizycki (1999), Hendricks (1996) and Jackson, Maude and Perraudin (1998).
} 


$$
\operatorname{Pr}(\Delta P(\Delta x, \Delta t)<\operatorname{VaR})=\alpha
$$

This simply states that the probability that the change in the value of the portfolio, $\Delta P$, (which is a function of the holding period, $\Delta t$, and changes in the prices of assets held in the portfolio, $\Delta x$ ) is less than the Value-at-Risk is equal to the significance level $\alpha$. Figure one shows the Value-at-Risk for the distribution of returns calculated using a confidence interval of $99 \%$, i.e. a significance level, $\alpha$, of $1 \%$. Throughout our analysis the holding period is set at one day. However, we adopt one of four horizons for the estimation period of the variance covariance matrix. They are 50 days, 125 days, 250 days and 500 days or approximately two months, six months, one year and two years. Furthermore, by adopting similar horizons to the previous literature, Hendricks (1996) and Engel and Gizycki (1999), our results will be directly comparable. In addition, we set two significance levels, namely $1 \%$ and $5 \%$. For these differing combinations we then assess the performance of differing forecasting models, adopting both parametric and nonparametric methodologies. The sensitivity of the results gained from these differing approaches are of interest and importance for regulators and other endusers of Value-at-Risk.

The adoption of a portfolio of foreign exchange positions means that we have a linear relationship and we therefore can concentrate solely on the relative merits of different forecasting techniques, rather than the assumptions regarding any non-linear relationships. Furthermore, throughout our analysis, we assume that expected returns on the assets are zero. Gizycki and Hereford (1998) find that many banks adopt zero means for their own in-house VaR calculations, while Jackson et al. (1997) claim that poorly determined estimates of the mean will reduced the efficiency of the variance covariance matrix estimated for use in the VaR.

The first two models that will be considered are parametric approaches. These are the variance-covariance approaches which assume normality and serial independence. The equally weighted variance-covariance method places equal significance on each observation in the forecast horizon window, while the exponentially weighted moving average method allows for greater emphasis to be 
placed on more recent observations. For both approaches, we can define $R_{t}$ as the matrix of returns on the currencies, and $\Sigma_{t}$ as the variance covariance matrix of $R_{t}$. In addition, we can define a vector of sensitivities, $\delta$, which measure the measure the sensitivity of the portfolio to changes in risk factors. The change in portfolio value is then:

$$
\Delta P \sim N(0, \delta \Sigma \delta)
$$

Which solving for the Value-at-Risk gives:

$$
V a R=-Z(\alpha) \sqrt{\delta \Sigma \delta}
$$

Where $\mathrm{Z}(\alpha)$ is the $100 \alpha^{\text {th }}$ percentile of the standard normal distribution, such that if $\alpha$ is 99 then $Z(\alpha)$ is 2.33 .

The two approaches that are adopted in this study estimate the variance covariance matrix in the following way: using the equally weighted approach, the variance covariance matrix is estimated by:

$$
\hat{\Sigma}_{t+1}=\frac{1}{T} \sum_{s=0}^{T-1} R_{t-s} R_{t-s}^{\prime}
$$

However if the variance covariance matrix varies over time, then relatively old observations should be ignored, the emphasis being placed on recent data. The exponentially weighted moving average approach defines a weight $\lambda$, known as the "decay factor", which allows for greater importance to be placed upon more recent observations when calculating the variance covariance matrix. In this study we adopt three different values for $\lambda, 0.99,0.97$ and 0.94 . The lower the value of $\lambda$, the greater the weight placed upon more recent events. Using the exponentially weighted moving average approach, the variance covariance matrix is estimated by:

$$
\hat{\Sigma}_{t+1}=(1-\lambda) \sum_{s=0}^{T-1} \lambda^{s-1} R_{t-s} R_{t-s}^{\prime}
$$


While the exponentially weighted moving average model captures volatility clustering, a richer description of behaviour is provided by the Generalised Autoregressive Conditional Heteroscedasticity (GARCH) models proposed by Bollerslev (1986). These models allow for both autoregressive and moving average behaviour in variances and covariances. e.g. the univariate zero-mean $\operatorname{GARCH}(1,1)$ model has the form:

$$
\sigma_{t+1}^{2}=\omega+\alpha R_{t}^{2}+\beta \sigma_{t}^{2}
$$

where the parameters $\omega, \alpha$ and $\beta$ are estimated using quasi maximum likelihood methods.

Alexander (2001) states that evidence suggests that long-term forecasts are more realistic when generated by GARCH models as opposed to exponentially weighted moving average models. Additionally, Alexander and Leigh (1997) analyse the performance of Value-at-Risk models using the equally weighted average, the exponential weighted average and the GARCH approach. They provide mixed evidence on the competing methodologies. They find that while the exponentially weighted moving average approach is the most accurate at predicting the centre of the distribution, the tails, and therefore the VaR measure may be too low. Thus, although the exponentially weight moving average approach may be the most accurate it is the GARCH and equally weighted methodologies which are superior operationally.

In a multivariate setting, for any element of the full variance covariance matrix we can express the time dependent nature of the formulation as:

$$
\sigma_{i j, t+1}=f\left(R_{i, t}, R_{j, t}, \sigma_{i j, t}\right) \quad \forall i, j
$$

However, the number of parameters to be estimated in such GARCH models means that as the number of risk factors increases then computation rapidly 
becomes intractable. ${ }^{[}$There have subsequently been a number of developments in the literature aimed at circumventing this problem. ${ }^{\text {B }}$ Engle and Kroner (1995) proposed the BEKK formulation which has been widely adopted in empirical work as a tractable methodology. However, the number of parameters to be estimated can still be large and interpretation of the parameter coefficients is difficult. Engle (2000) developed a new class of models, Dynamic Conditional Correlation (DCC) multivariate GARCH, which reduces further the number of parameters to be estimated. Further analysis of this approach is provided by Engle and Sheppard (2001). However, in this study, we adopt a solution proposed by Engle, $\mathrm{Ng}$ and Rothschild (1990) which exploits factor analysis to enable a small number of factors to describe a high proportion of the structure of the variance covariance matrix. This concept was initially extended by Alexander and Chibumba (1998) who propose an 'orthogonal' GARCH model. Firstly their approach orthogonalises the risk factors. These orthogonal risk factors are known as the 'principle components'. Since these are, by definition, orthogonal to each other, we no longer need to measure the covariances, substantially reducing the number of parameters needing to be estimated. The approach developed further by Alexander (2000, 2001, 2002) can be outlined as follows:

Define the matrix $R$ ( $T$ by $k$ ) to contain the full set of historical returns. Let $W$ ( $k$ by $k$ ) be the matrix of eigenvectors of $R^{\prime} R$. The orthogonal principle components are then the columns $\left[P_{1} \ldots P_{k}\right]$ of:

$$
P=\left[P_{1} \ldots P_{k}\right]=R W
$$

Solving for $R$ and using the property of $W$ that its inverse is equal to its transpose, it is possible to write the change of in risk factor $I$ as a linear combination of the principle components where the weights by the elements of the $i^{\text {th }}$ eigenvector:

\footnotetext{
${ }^{5}$ As noted by Alexander (2002, p.38) "the implementation of these models in more than a few dimensions is extremely difficult: because the model has very many parameters, the likelihood function becomes very flat, and consequently the optimization of the likelihood function become practically impossible."

${ }^{6}$ A discussion of the development of multivariate GARCH models is provided by Engle and Sheppard (2001).
} 


$$
\begin{gathered}
R=P W^{\prime} \\
\Rightarrow R_{i}=\omega_{i 1} P_{1}+\omega_{i 2} P_{2}+\ldots+\omega_{i k} P_{k}
\end{gathered}
$$

The estimate of $\Sigma_{t}$ is then given by:

$$
\hat{\Sigma}_{t}=W \operatorname{var}(P) W^{\prime}
$$

Note that only the eigenvectors of $R^{\prime} R$, and the diagonal elements of $\operatorname{var}(P)$ need to be estimated to obtain $\hat{\Sigma}_{t}$. More importantly, each of the principalcomponent variances can be modelled independently, in a univariate setting, using a GARCH framework.

Engle (2000) evaluates the performance of these three alternative multivariate GARCH methodologies. While he concludes that his DCC model performs best, he finds that the O-GARCH formulation performs very well in the majority of tests, with both models clearly outperforming the BEKK specifications.

Non parametric estimation allows for the adoption of modelling approaches that make no assumptions regarding the statistical distribution of the returns data. Figure two highlights the difference in the distribution of returns between a normal distribution and a distribution which is characterised by excess kurtosis, i.e. fat tails. Exchange rate returns are characterised by excess kurtosis. If this is indeed the case, then adopting a VaR estimated assuming a normal distribution will result in an under estimation of the 'true' VaR in the presence of fat tails. Using a non parametric approach allows us to analyse whether exchange rate returns are best characterised by a normal distribution or otherwise. The most widely used approach is that of Historical Simulation (HS). This technique uses past price movements to calculate a hypothetical distribution of returns on the current portfolio. This provides a series of changes in portfolio value that would have been realised had the current portfolio been held over the period in question. The Valueat-Risk is then set equal to the percentile of the return distribution given a required level of confidence. 


\section{0: Model Evaluation}

There is no definitive measure of $\mathrm{VaR}$ model performance, thus in order to evaluate the performance of the competing models, we present a variety of different metrics which provide an indication of model performance.

Firstly we considered the variability in the VaR estimates produced by the different models. This enables us to assess whether a particular model produces higher risk estimates relative to the other models. Such a model, which consistently yields a higher VaR measure, would be regarded as being conservative.

Secondly, we attempt to capture the accuracy of the different models by evaluating the extent to which the proportion of losses that exceed the VaR estimate is consistent with the models' stated confidence level.

\section{1: Measures of Relative Size and Variability}

To assess the relative size of the $\mathrm{VaR}$ estimates produced by the various models we apply the mean relative bias statistic developed by Hendricks (1996). This statistic captures the extent to which different models produce estimates of similar average size. Given $T$ time periods, and $N$ VaR models, the mean relative bias of any model $i$ is calculated as:

$$
M R B_{i}=\frac{1}{T} \sum_{t=1}^{T} \frac{V a R_{i t}-\overline{V a R}_{t}}{\overline{\operatorname{VaR}}_{t}} \quad \text { where } \overline{\operatorname{VaR}}_{t}=\frac{1}{N} \sum_{i=1}^{N} V a R_{i t}
$$

Hendricks (1996) extends the simple mean relative bias statistic to capture the variability of the model estimates, in addition to the extent to which the model average differs from the average of all models. This measure, known as the root mean squared relative bias, is calculated as: 


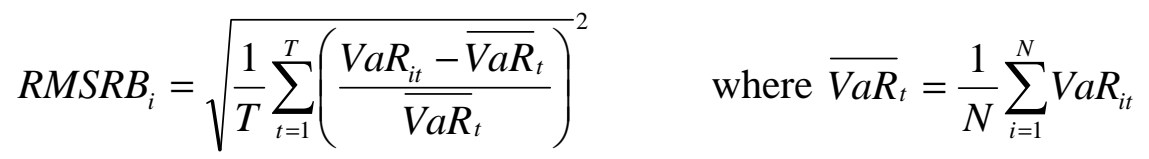

\section{2: Interval Forecasts}

Christoffersen (1998) has designed a three step procedure for the evaluation of interval forecasts: a test for "unconditional coverage", a test for "independence" and a test for "conditional coverage". All three tests are performed using the likelihood ratio framework. The test for unconditional coverage tests a null hypothesis that the probability of failure or exception, i.e. the $\mathrm{VaR}$ forecast is exceeded, is $p$ against an alternative that the probability differs from $p$ assuming the failure process is independently distibuted.

The test is calculated as:

$$
L R_{u c}=-2 \ln \left[\frac{p^{n_{I}}(1-p)^{n_{o}}}{\hat{\pi}^{n_{I}}(1-\hat{\pi})^{n_{0}}}\right] \sim \chi_{1}^{2}
$$

where:

$p$ is the desired significance level, i.e. one minus the VaR confidence level.

$n_{0}$ is the number of times in the sample when the VaR forecast is not exceeded. $n_{l}$ is the number of times in the sample when the VaR forecast is exceeded.

$$
\hat{\pi}=\frac{n_{1}}{n_{0}+n_{1}}
$$

However a poor interval forecast may still produce correct unconditional coverage but not capture the higher-order dynamics of the series. Although the test for correct unconditional coverage can be utilised to penalise firms it does not capture asymmetries or leverage effects which will affect the accuracy and efficiency of any forecasts.

The test for independence tests the hypothesis that the failure process is independently distributed against an alternative that the process follows a first order Markov process. The test is calculated as: 


$$
L R_{\text {ind }}=-2 \ln \left[\frac{\left(1-\hat{\pi}_{2}\right)^{\left(n_{00}+n_{10}\right)} \hat{\pi}_{2}^{\left(n_{01}+n_{l 1}\right)}}{\left(1-\hat{\pi}_{01}\right)^{n_{00}} \hat{\pi}_{01}^{n_{01}}\left(1-\hat{\pi}_{11}\right)^{n_{10}} \hat{\pi}_{11}^{n_{11}}}\right] \sim \chi_{1}^{2}
$$

where:

$$
\begin{aligned}
& n_{i j}=\text { number of } i \text { values followed by a } j \text { value in the series, } i, j=0,1 \\
& \pi_{i, j}=\operatorname{Pr}\left\{I_{t}=i \mid I_{t-1}=j\right\} \quad i, j=0,1 \\
& \hat{\pi}_{01}=\frac{n_{01}}{n_{00}+n_{01}}, \hat{\pi}_{11}=\frac{n_{11}}{n_{10}+n_{11}} \text { and } \hat{\pi}_{2}=\frac{n_{01}+n_{11}}{n_{00}+n_{01}+n_{10}+n_{11}}
\end{aligned}
$$

A tighter requirement is that a VaR model provides correct "conditional" coverage. If a VaR model has the ability to capture the conditional distribution of returns and its dynamic properties such as time varying volatility accurately, then exceptions should be unpredictable. The importance of testing "conditional" coverage stems from the observation that the majority of financial time series exhibit volatility clustering. As a consequence, superior interval forecasts should be narrow during tranquil periods and in volatile periods such that exceptions are spread across a sample and do not appear in clusters. The test for correct conditional coverage is calculated as:

$$
L R_{c c}=-2 \ln \left[\frac{p^{n_{I}}(1-p)^{n_{0}}}{\left(1-\hat{\pi}_{01}\right)^{n_{00}} \hat{\pi}_{01}^{n_{01}}\left(1-\hat{\pi}_{11}\right)^{n_{10}} \hat{\pi}_{11}^{n_{11}}}\right] \sim \chi_{2}^{2}
$$

\section{3: Measures of Accuracy}

Lopez (1999) proposes a regulatory loss function in order to assess the accuracy of the VaR estimates. The general form of the loss function for bank $i$ at time $t$ is:

$$
L_{i, t+1}=\left\{\begin{array}{ccc}
f\left(\Delta P_{i, t+1}, V a R_{i, t}\right) & \text { if } & \Delta P_{i, t+1}<\operatorname{VaR}_{i, t} \\
g\left(\Delta P_{i, t+1}, V a R_{i, t}\right) & \text { if } & \Delta P_{i, t+1} \geq V a R_{i, t}
\end{array}\right.
$$

where $f()$ and $g()$ are functions that satisfy $f() \geq g()$ and $\Delta P$ represents the realised profit or loss. In this paper we consider two specific loss functions - a 
binary loss function which takes account of whether any given days loss is greater or smaller than the $\mathrm{VaR}$ estimate and a quadratic loss function which also takes account of the magnitude of the losses that exceed the VaR estimate.

The binary loss function treats any loss larger than the VaR estimate as an 'exception'. Thus we are concerned with the number of exceptions rather than the magnitude of these exceptions. Each loss which exceeds the $\mathrm{VaR}$ is assigned an equal weight of unity, while all other profits and losses have a zero weight. i.e.

$$
L_{i, t+1}=\left\{\begin{array}{lll}
1 & \text { if } & \Delta P_{i, t+1}<V a R_{i, t} \\
0 & \text { if } & \Delta P_{i, t+1} \geq V a R_{i, t}
\end{array}\right.
$$

If the VaR model is truly providing the level of coverage defined by its confidence level, then the average binary loss function over the full sample will be equal to 0.05 for the $95 \%$ VaR estimate and 0.01 for the $99 \%$ VaR estimate.

The quadratic loss function takes account of the magnitude of the exception. Lopez (1999) found that the quadratic loss functions use of the additional information embodied in the size of the exception provided a more powerful measure of the model accuracy than the binary loss function. In addition to taking account of the magnitude of the exception, the application of the quadratic functional form penalises large exceptions more severely than a linear or binary measure. The quadratic loss function is defined as:

$$
L_{i, t+1}= \begin{cases}1+\left(\Delta P_{i, t+1}-V a R_{i, t}\right)^{2} & \text { if } \Delta P_{i, t+1}<\operatorname{VaR} R_{i, t} \\ 0 & \text { if } \Delta P_{i, t+1} \geq \operatorname{VaR} R_{i, t}\end{cases}
$$

Sarma et al (2000) suggest that a loss function of the form above captures the goals of the financial regulator, referring to it as a regulatory loss function.

\section{0 : Data and Empirical Results}

The data used in the construction of the portfolio are foreign exchange data from $4^{\text {th }}$ January 1990 to $17^{\text {th }}$ December 1998 provided by the Bank of Ireland, it consists of daily exchange rates against the Irish Punt for the following six 
currencies, UK sterling, US dollar, Italian lira, Dutch guilder, French franc and German deutschemark. We estimate all the models from $11^{\text {th }}$ February 1992 onwards (a sample of 1785 days) to allow for the largest window horizon of 500 days. The sample under investigation includes both the highly volatile period of the early 1990's, culminating in the currency crisis of 1992, and the run up to EMU. We also analyse the performance of the models over a shorter time period, $1^{\text {st }}$ July 1993 to $17^{\text {th }}$ December 1998, (a sample of 1425 days) which removes the 1993 devaluation of the punt.

Table 1 presents some descriptive statistics for each of these returns while figures $3 \mathrm{a}-3 \mathrm{f}$ plot the returns series for all six currencies. Volatility clustering would appear to be evident from each of the exchange rate series and the $10 \%$ devaluation in the Irish Punt which occurred on January $30^{\text {th }} 1993$ can clearly be seen in all series.

Figures $4 \mathrm{a}$ and $4 \mathrm{~b}$ show the estimated VaR using the standard variance covariance (VCV) approach and the actual returns for the 50 day estimation window and the 500 day window respectively. ${ }^{8}$ It can clearly be seen that shorter estimation windows are prone to swings in the data as results rely solely on recent events, allowing estimates to capture the volatility of the market. The VaR estimates using a longer window length are more stable. The larger window sizes essentially treat the series as homoscedastic, i.e. $\sigma_{t}$ varies negligibly and the VaR estimates remain stable. Next we compare the estimated VaR using the exponentially weighted moving average (EWMA) variance covariance approach for $\lambda$ equal to 0.94 .2 It can clearly be seen, see figures $5 \mathrm{a}$ and $5 \mathrm{~b}$, that the series generated with $\lambda=0.94$ is almost entirely dependent upon recent observations and is therefore highly variable.

We now compare the standard techniques with two alternatives, a parametric approach, the Orthogonal GARCH $(\mathrm{O}-\mathrm{GARCH})$ specification, and a

\footnotetext{
${ }^{7}$ We would like to thank an anonymous referee for this suggestion.

8 The charts presented show the results from using the 50 day and 500 day windows, i.e. the two extremes in this study. The findings for the 125 and 250 day windows lie between these two. These results are available from the authors on request.

${ }^{9}$ We also ran the VaR for $\lambda=0.99$ and 0.97 , results available from the authors on request.
} 
non-parametric approach, the historical simulation methodology. The results for the O-GARCH approach would appear to be much more responsive to the swings in the data, see figures $6 a$ and $6 \mathrm{~b}$. The VaR estimates produced by the O-GARCH model seem to have greater accuracy than those produced by the other parametric approaches. We also look at a non-parametric approach, historical simulation, to compare the results. Although this procedure has the added advantage of dropping the normality assumption, the results would appear to be relatively poor, see figures $7 \mathrm{a}$ and $7 \mathrm{~b}$.

As can be seen there is no definitive measure of VaR model performance, thus in order to evaluate the performance of the competing models, we present some metrics that provide an indication of model performance. The Mean Relative Bias (MRB) and Root Mean Squared relative Bias (RMSRB) statistics are presented in tables 2 and 3. Sections a and b show the mean relative bias and root mean squared relative bias statistics for the $95 \%$ and $99 \% \mathrm{VaR}$. The results show that there is some degree of variation between the competing models, e.g. at the 500 day horizon the mean relative bias statistics fall between 15 (the VCV model) and 11 per cent (the HS approach) highlighting that of the approaches considered, the VCV and HS models are the least accurate. The EWMA $(\lambda=0.94)$ model remains very close to the mean over all horizons and the O-GARCH model also performs well. The root mean squared relative bias statistics support these initial findings, showing that the EWMA $(\lambda=0.94)$ model again varies little in magnitude from the average risk estimate. However the O-GARCH suffers due to the relative conservatism of this average figure. 10

The results of the interval forecast analysis are reported in tables 4 (95\% $\mathrm{VaR})$ and $5(99 \% \mathrm{VaR})$. It can be seen that while a number of models (e.g. 50 day $\mathrm{VCV}$ ) may produce correct unconditional coverage they do not exhibit correct conditional coverage. Again the likelihood ratio tests show that the performance of the O-GARCH and EWMA $(\lambda=0.94)$ models tends to be superior to the other

\footnotetext{
${ }^{10}$ The O-GARCH model may be more accurate than the EWMA models. However, since the EWMA models are close to the mean, the measured RMSRB statistic punishes models for deviating from the mean, even if this is due to greater accuracy. This is supported by the results of the sample omitting the devaluation.
} 
contenders. However the EWMA $(\lambda=0.94)$ model edges the O-GARCH model given the null can be rejected for the LR tests in only 7 cases compared with 11 cases.

We finally look at the results using the previously discussed Lopez (1999) loss functions. The results given by both the binary loss function and the quadratic loss function are reported in tables $2 \mathrm{c}$ and $2 \mathrm{~d}$ and tables $3 \mathrm{c}$ and $3 \mathrm{~d}$. The performance of each of the models is broadly similar according to both functions, although the O-GARCH model and the EWMA $(\lambda=0.94)$ seem to out perform the other competing specifications.

When we analyse the models over the shorter sample period, omitting the 1993 devaluation, we find the evaluation statistics improve significantly for the OGARCH model. The evaluation statistics are reported in tables 6 and 7. These results clearly show that the statistics for the full sample period suffer due to the devaluation. While the O-GARCH specification captures the devaluation accurately it is penalised because in doing so it moves away from the mean. Once the large devaluation is omitted from the sample, the statistics suggest that the O-GARCH is the most appropriate model. However, the tests of conditional coverage, reported in tables 8 and 9, still marginally favour the EWMA $(\lambda=0.94)$ specification over the O-GARCH even with the shorter sample.

Overall, the results of the evaluation of model accuracy would appear to be consistent with the graphical evidence. There is clearly a trade off between accuracy and conservatism. The O-GARCH specification clearly generates the most accurate VaR estimates, however, it is the least conservative approach. Alternatively, the EWMA $(\lambda=0.94)$ model is more conservative but is less accurate. These methodologies are superior to the others considered here, furthermore we would contend that from a viewpoint of striking a balance between conservatism and accuracy the EWMA $(\lambda=0.94)$ specification should be the preferred choice, due to its performance in the tests of conditional coverage. 


\section{0 : Conclusions}

Given that banks can now adopt their own in-house models, it has become important to assess the relative performance of the various models. The importance of the differing techniques has been a topic of a number of recent finance papers, however this is the first known study explicitly taking into consideration the issues from an Irish perspective. Given the historical (and continued) importance of foreign exchange rate risk to a small open economy like Ireland, we have focused primarily on the measurement and evaluation of this form of risk. In this study we compare a number of methodologies for estimating Value-at-Risk that have proved popular. Specifically, we consider the standard variance covariance approach, the exponential weighted moving average (EWMA) approach, the Orthogonal GARCH specification, and historical simulation methodology.

Using an equally weighted portfolio of foreign exchange positions in the currencies of Ireland's six major trading partners, we calculate the Value-at-Risk on the portfolio via each approach. Each methodology is used to estimate the one day $\mathrm{VaR}$ using a variance covariance estimated with a window of 50, 125, 250 and 500 days. We then adopt recently developed techniques which enable the evaluation of the performance and accuracy of these estimates. These evaluation tests are of crucial importance for both the bank/firm and the supervisory bodies. The results from the accuracy tests would appear to be consistent with the graphical evidence, in that the EWMA $(\lambda=0.94)$ and O-GARCH would appear to outperform the other models under consideration. We find that the O-GARCH model generates the most accurate VaR measures, however we argue that the EWMA $(\lambda=0.94)$ is the most appropriate model. Both the O-GARCH specification and the EWMA $(\lambda=0.94)$ approach provide VaR estimates that have greater accuracy and would improve efficiency for those needing to comply with capital adequacy requirements. However, the EWMA $(\lambda=0.94)$ is also acceptable to policy makers and supervisory bodies who may wish to impose a model that produces more conservative estimates than the O-GARCH approach. Although highly important in the case of Ireland, foreign exchange rate risk represents the simplest component of market risk. In future research we hope to analyse more complex issues such as yield curve 
structures that must be considered for interest rate markets and issuer specific risk for equity markets. 


\section{References}

Alexander, C. (2001) "Orthogonal GARCH" in Mastering Risk Volume 2, FT Prentice Hall, pp. 21-38.

Alexander, C. (2002) "Principal component Models for Generating Large GARCH Covariance Matrices”, Economic Notes, 31(2), pp. 337-359.

Alexander, C. and A. Chibumba (1998) "Orthogonal GARCH: An Empirical Validation on Equities, Foreign-Exchange and Interest Rates", working paper, University of Sussex.

Alexander, C. and C. Leigh (1997) "On the Covariance Matrices used in Valueat-Risk Models", Journal of Derivatives, 4(3), pp. 50-62.

Bollerslev, T. (1986) "Generalised Autoregressive Conditional Heteroskedasticity”, Journal of Econometrics, 31(3), pp. 307-327.

Browne, F., J. Fell, and S. Hughes (1994) "Derivatives: Their Contribution to Markets and Supervisory Concerns", Central Bank of Ireland Quarterly Bulletin, Autumn 1994.

Cassidy, C. and M. Gizycki (1997) "Measuring Market Traded Risk: Value-atRisk and Backtesting Techniques", Reserve Bank of Australia Discussion Paper No. 9708.

Christoffersen, P. (1998) "Evaluating Interval Forecasts", International Economic Review, 39, pp. 841-862.

Dowd, K. (1998) Beyond Value at Risk: The New Science of Risk Management, Wiley, Chichester, UK.

Engel, J. and M. Gizycki (1999) "Conservatism, Accuracy and Efficiency: Comparing Value at Risk Models", Australian Prudential Regulatory Authority Discussion Paper No. 2.

Engle, R. (2000) "Dynamic Conditional Correlation - A Simple Class of Multivariate GARCH Models", working paper, University of California, San Diego.

Engle, R. and K. Kroner (1995) "Multivariate Simultaneous GARCH" Econometric Theory, 11, pp. 122-150.

Engle, R., V. Ng and M. Rothschild (1998) "Asset Pricing with a Factor ARCH Covariance Structure: Empirical Estimates for Treasury Bills", NBER Technical Working Paper No. 65. 
Engle, R. and K. Sheppard (2001) "Theoretical and Empirical Properties of Dynamic Conditional Correlation Multivariate GARCH", working paper, University of California, San Diego.

Gizycki, M. and Hereford, N. (1998) "Assessing the Dispersion in Banks' Estimates of Market Risk: The Results of a Value-at-Risk Survey", Australian Prudential Regulatory Authority Discussion Paper No. 1 .

Guermat, C. and R.D.F. Harris (2001) "Robust Conditional Variance Estimation and Value-at-Risk", mimeo, University of Exeter.

Hendricks, D. (1996) "Evaluation of Value-at-Risk Models using Historical Data", Federal Reserve Bank of New York Economic Policy Review, April, pp. 39 - 69.

Hendricks, D. and B. Hirtle (1997) "Bank Capital Requirements for Market Risk: The Internal Models Approach", Federal Reserve Bank of New York Economic Policy Review, December, pp. 1 - 12.

Jackson, P., W. Perraudin and D. Maude (1998) "Testing Value-at-Risk Approaches to Capital Adequacy", Bank of England Quarterly Bulletin, 38(3), pp. $256-266$.

Jackson, P., D. Maude and W. Perraudin (1997) "Bank Capital and Value-atRisk", Journal of Derivatives, 4(3), pp. 73 - 89.

Jackson, P., D. Maude and W. Perraudin (1995) "Capital Requirements and Value-at-Risk Analysis", Institute for Financial Research, Birkbeck College Working Paper IFRI.

Jorion, P. (1997) Value at Risk: The New Benchmark for Controlling Market Risk, McGraw Hill, New York, US.

Lopez, J. (1999) "Methods for Evaluating Value-at-Risk Estimates", Federal Reserve Bank of San Francisco Economic Review, No. 02, pp. 3-17.

Sarma, M., Thomas, S. and A. Shah (2000) "Performance Evaluation of Alternative VaR Models", mimeo, Indira Gandhi Institute of Development Research.

Wilmott, P. (1998) Derivatives: The Theory and Practice of Financial Engineering, Wiley, Chichester, UK. 


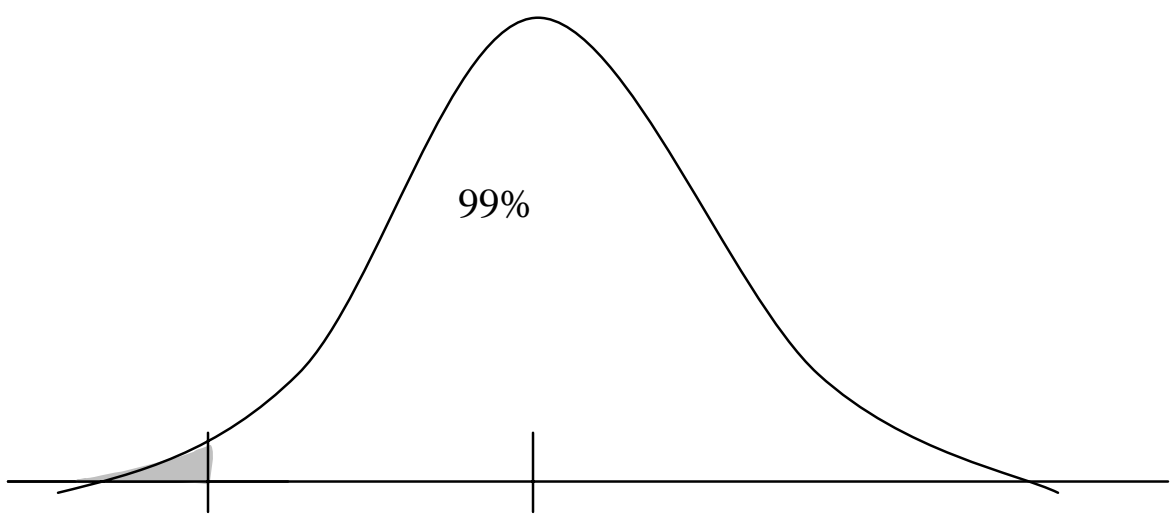

Value at Risk

Figure 1 : Value at Risk

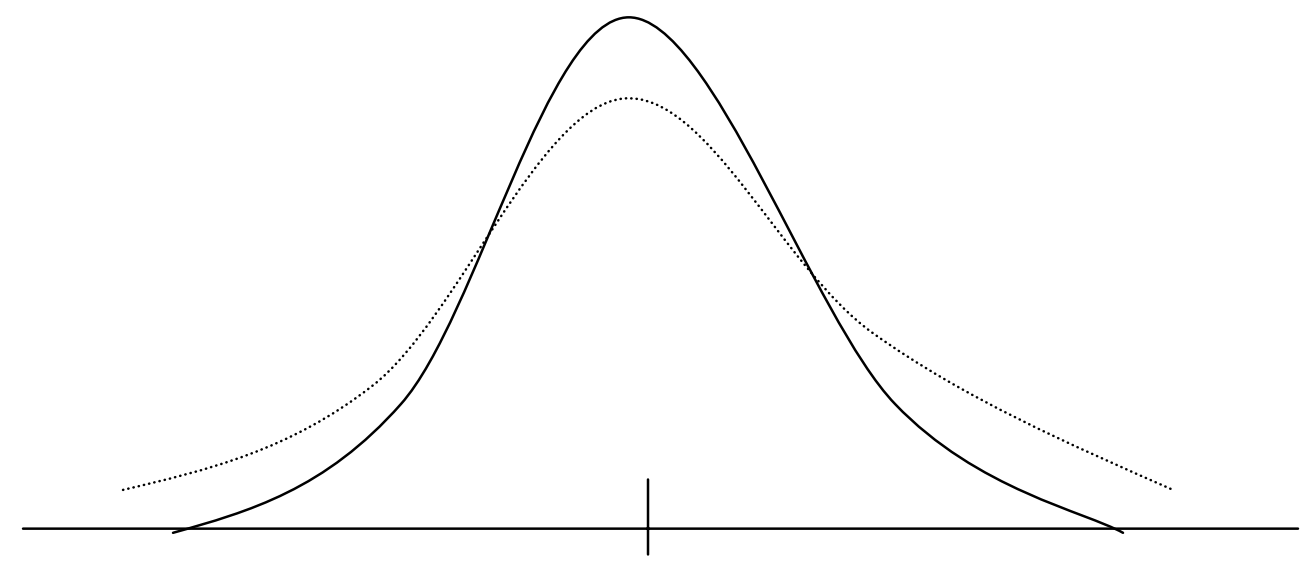

Figure 2 : Normal and Fat Tails 


\begin{tabular}{lcccc}
\hline & Mean $\left(\mathrm{x} 10^{-3}\right)$ & Standard Deviation & Maximum & Minimum \\
\hline \hline UK Sterling & -0.0261 & 0.0040 & 0.0465 & -0.0620 \\
US Dollar & 0.0058 & 0.0064 & 0.0336 & -0.0837 \\
Italian Lira & 0.1051 & 0.0046 & 0.0593 & -0.0745 \\
Dutch Guilder & -0.0198 & 0.0034 & 0.0324 & -0.0698 \\
French Franc & -0.0258 & 0.0037 & 0.0247 & -0.0707 \\
German Mark & -0.0195 & 0.0033 & 0.0220 & -0.0694 \\
\hline
\end{tabular}

Table 1 


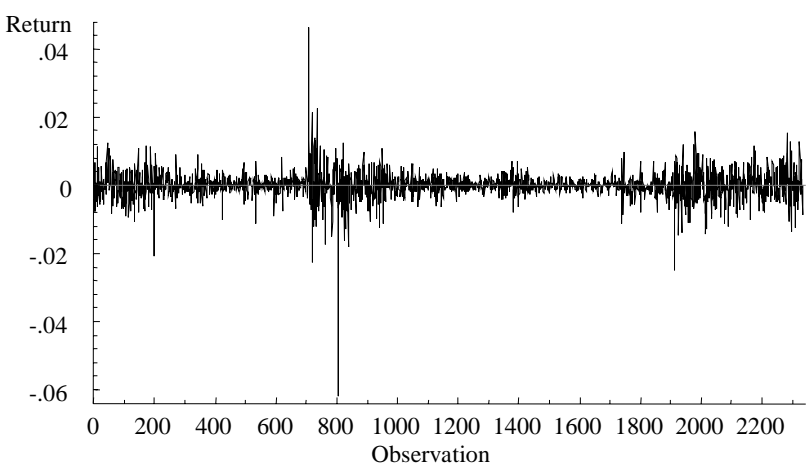

Figure 3a: UK

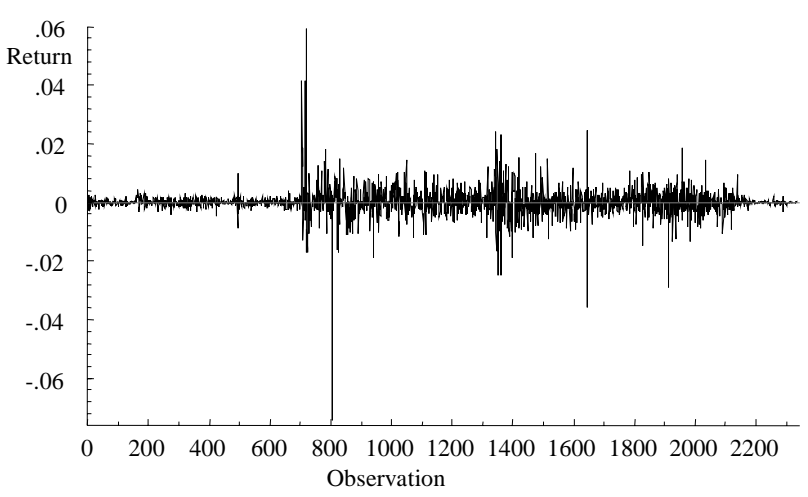

Figure 3c: Italy

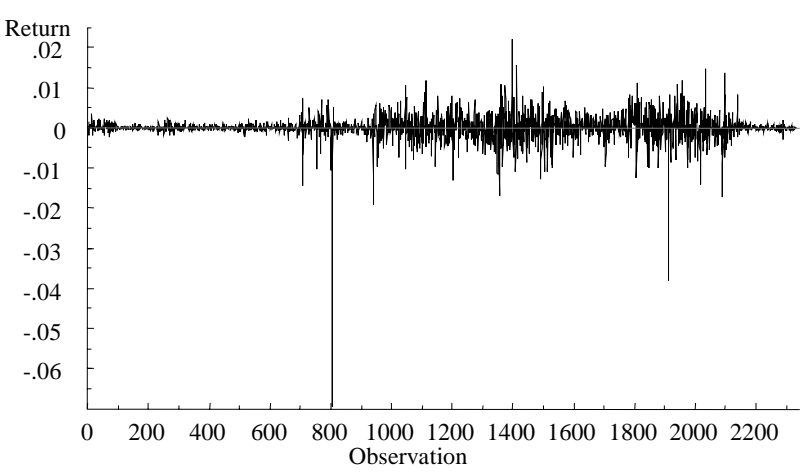

Figure 3e: France

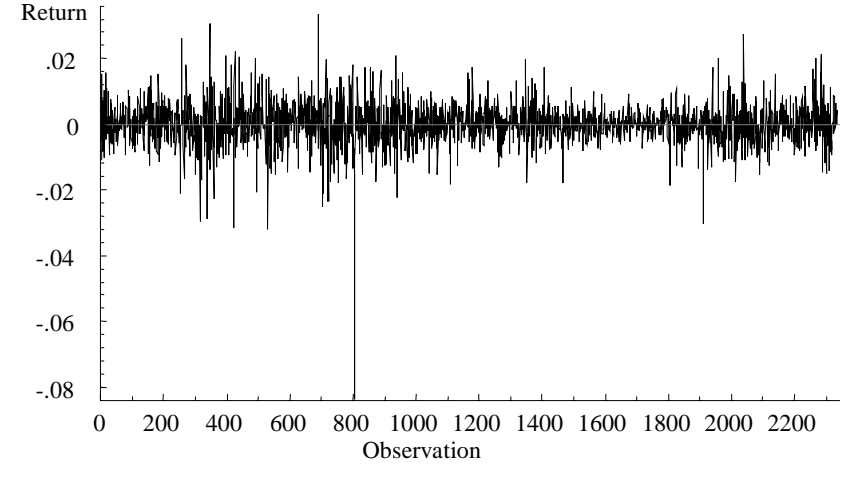

Figure 3b: US

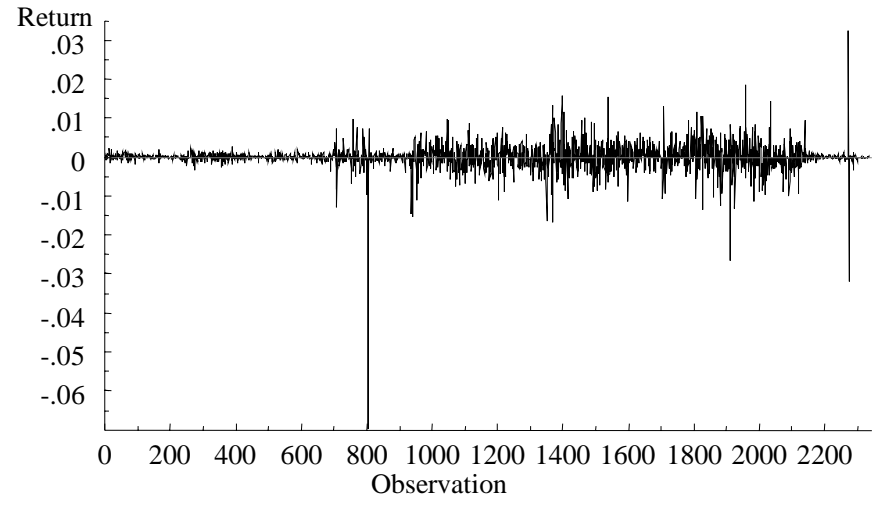

Figure 3d: Netherlands

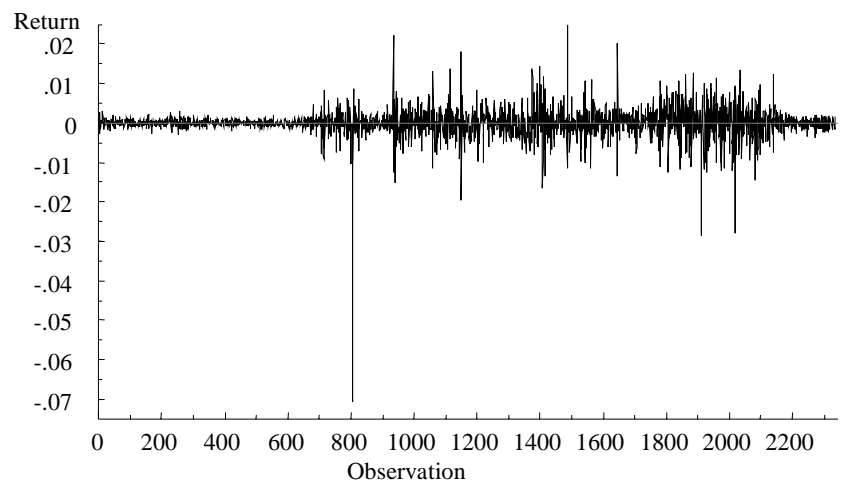

Figure 3f: Germany 
Figure 4: Actual Returns versus VaR Estimates: Variance Covariance Estimates

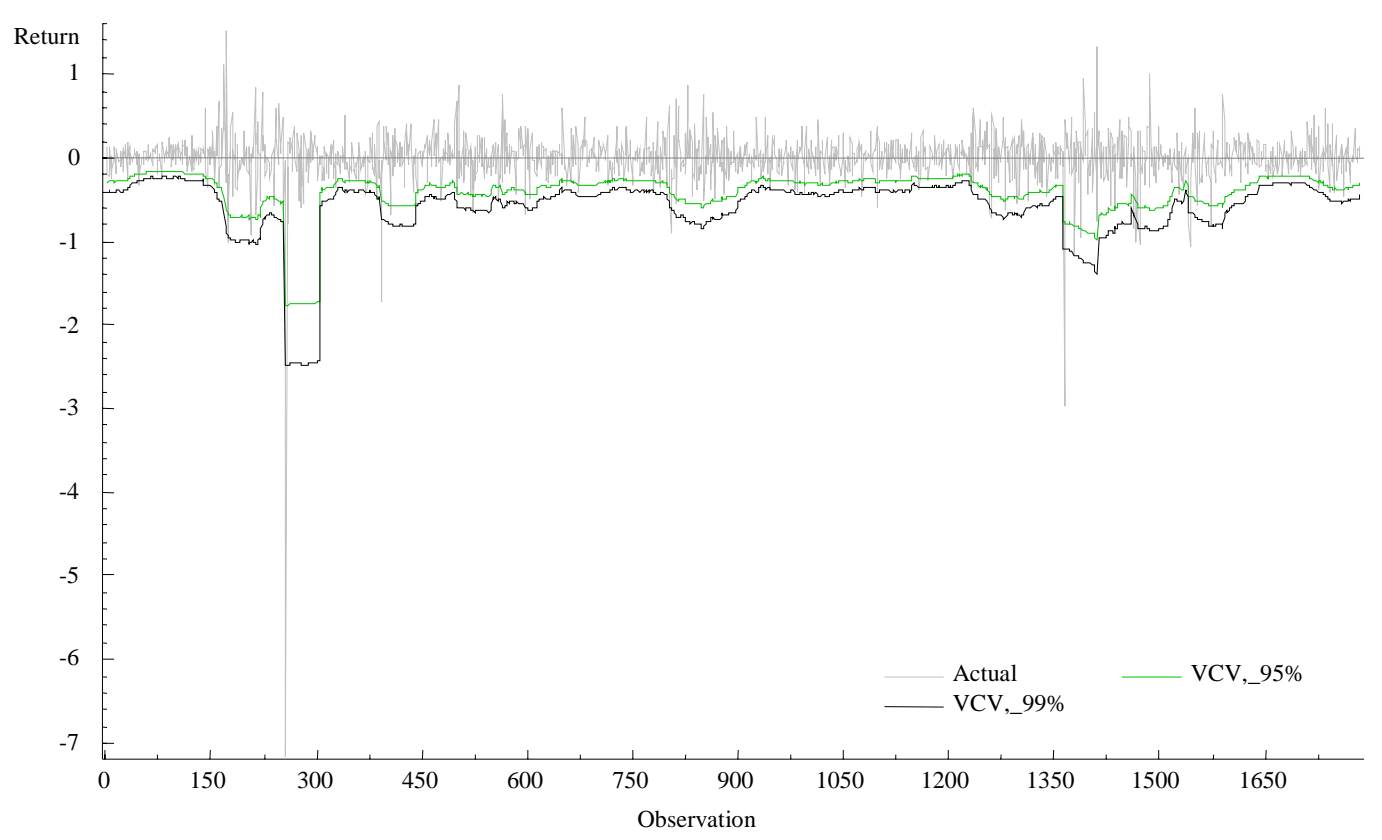

4a: 50 day window

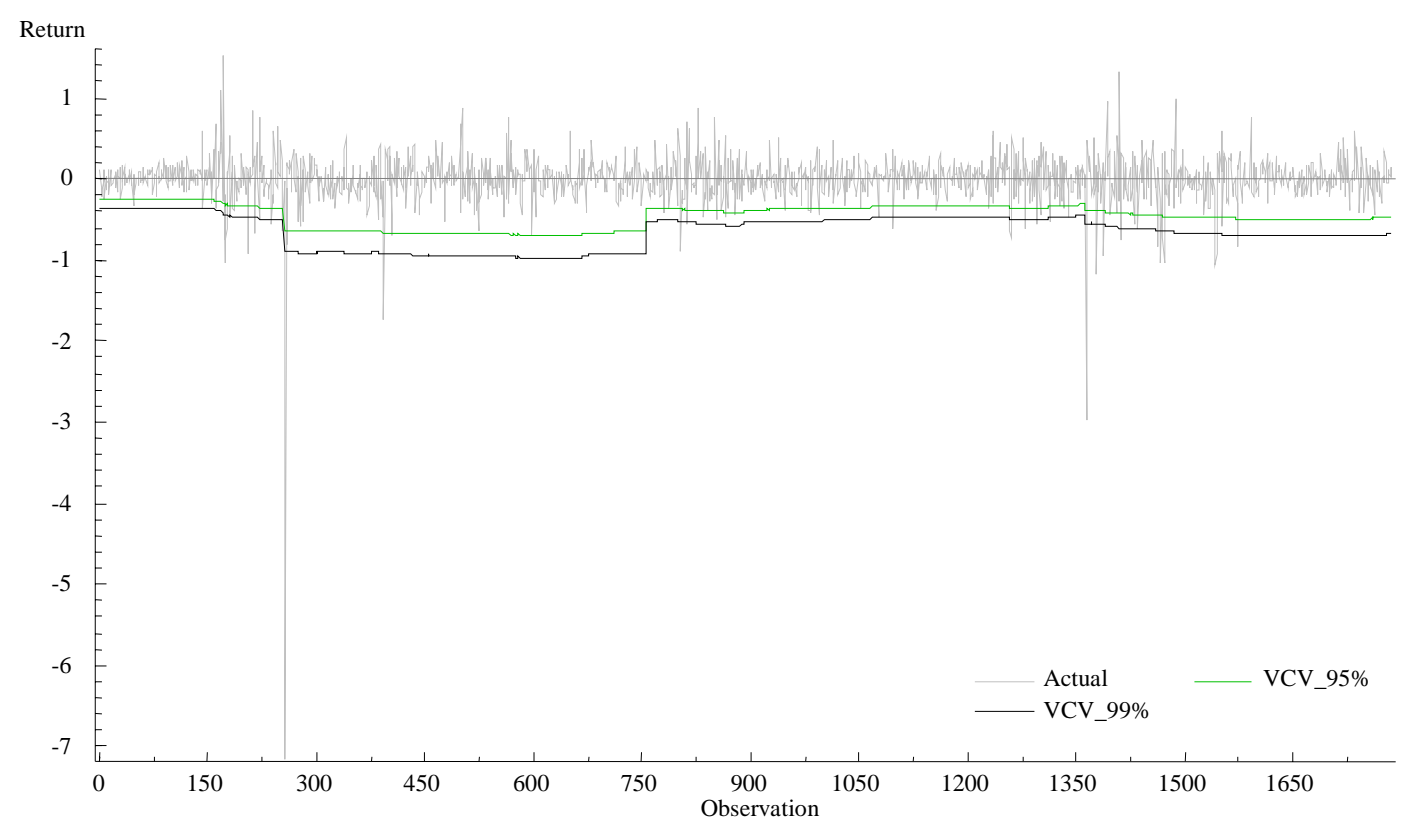

4b: 500 day window 
Figure 5: Actual Returns versus VaR Estimates: Exponentially Weighted Average Estimates

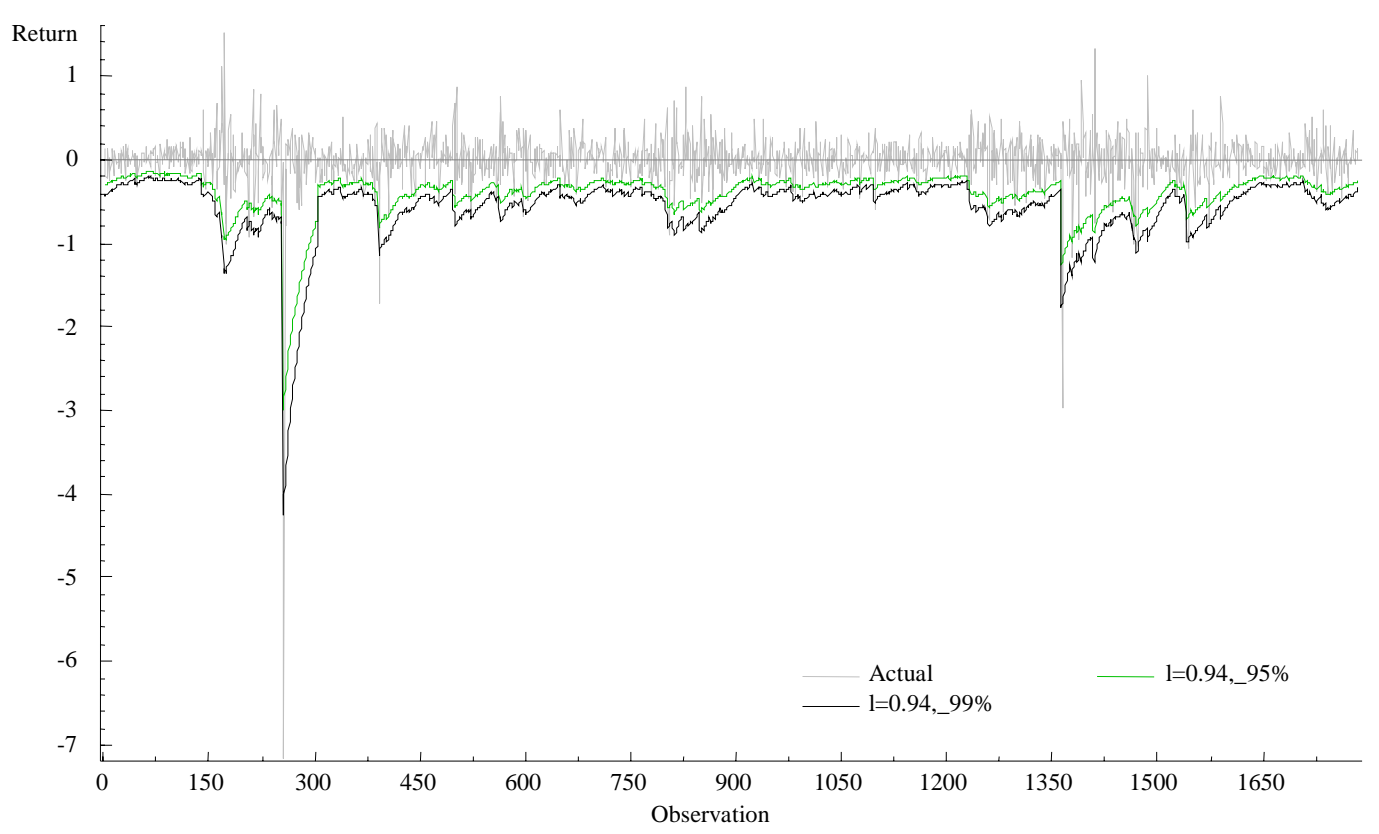

5a: $\lambda=0.94-50$ day window

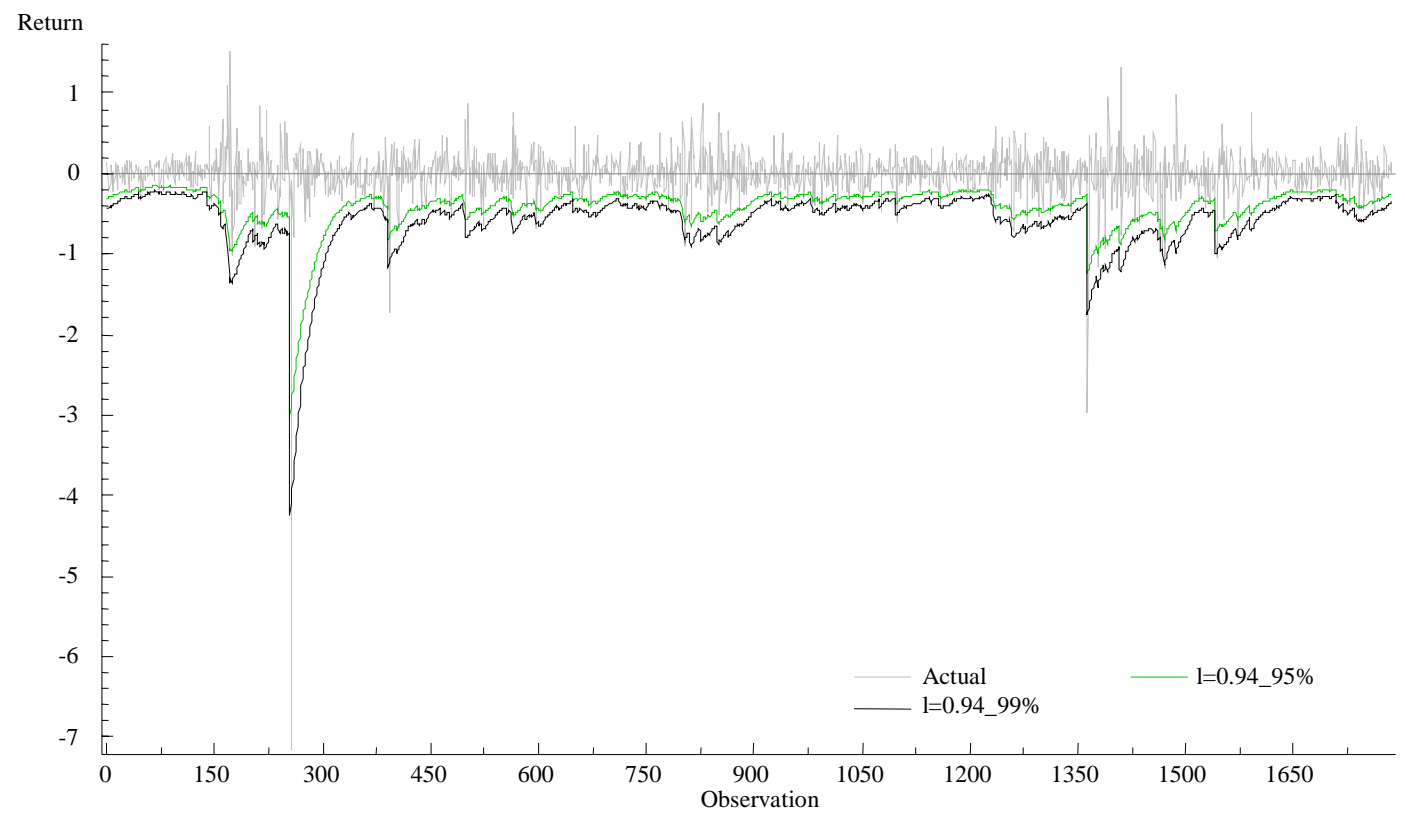

5b: $\lambda=0.94-500$ day window 
Figure 6: Actual Returns versus VaR Estimates: Orthogonal GARCH Estimates

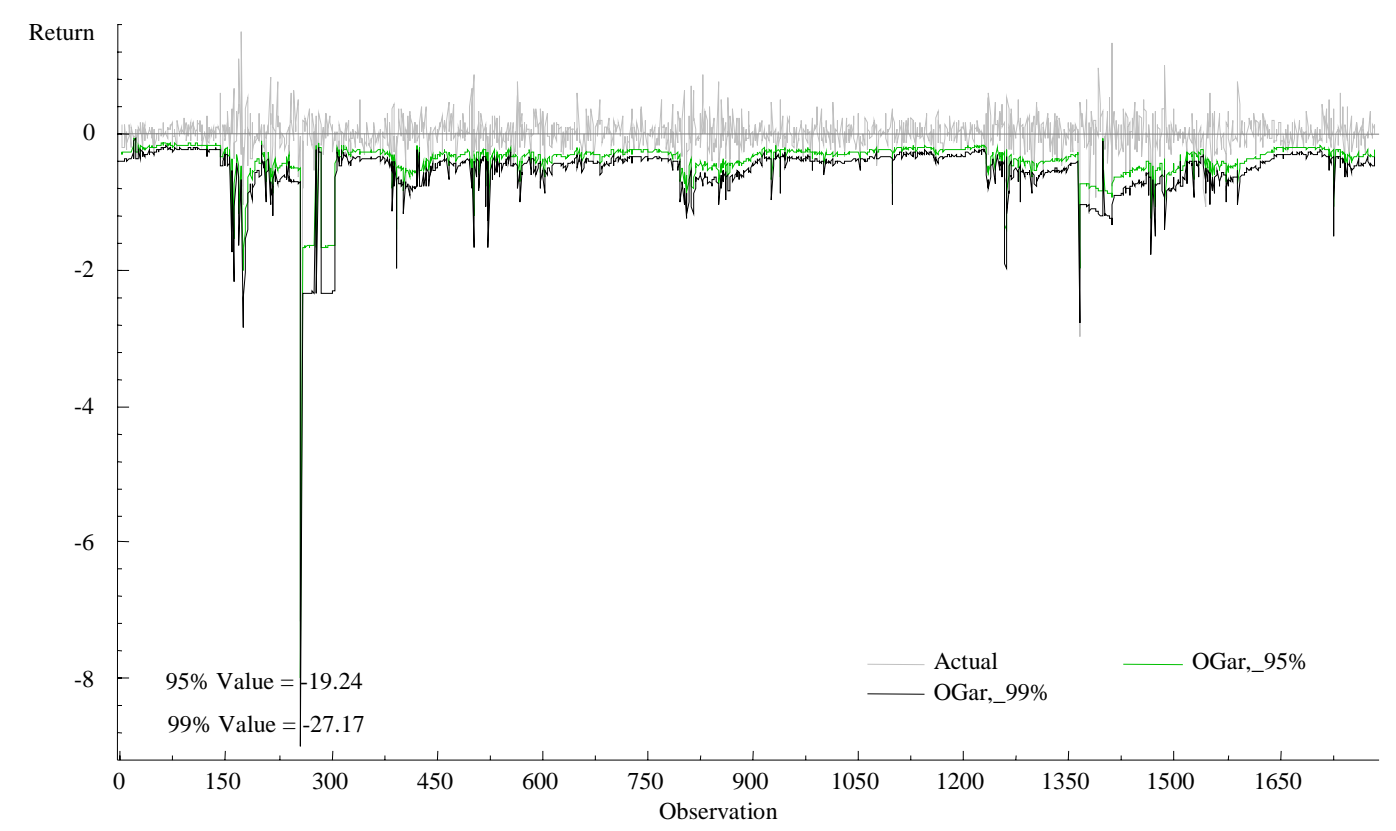

6a: 50 day window

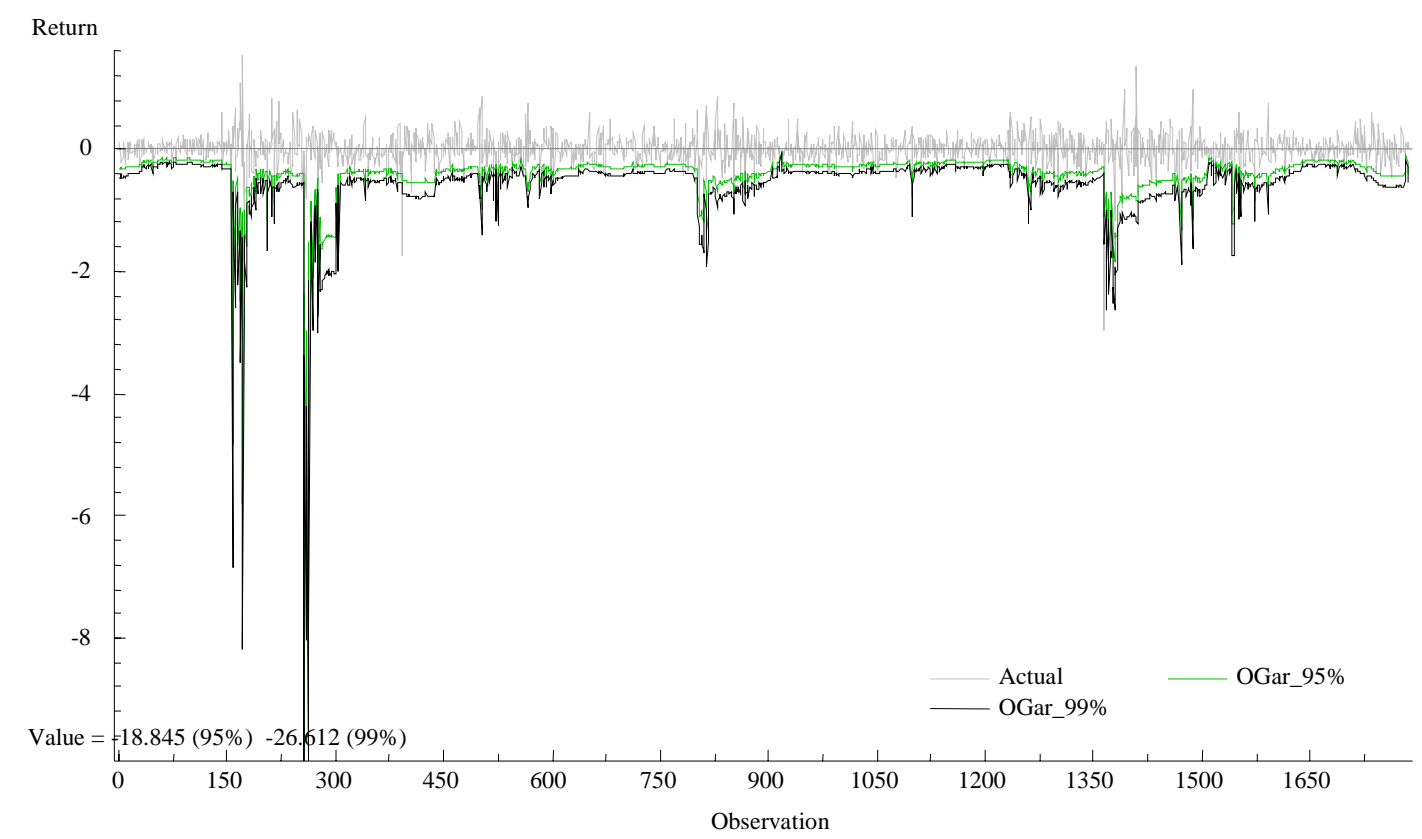

6b: 500 day window 
Figure 7: Actual Returns versus VaR Estimates: Historical Simulation Estimates

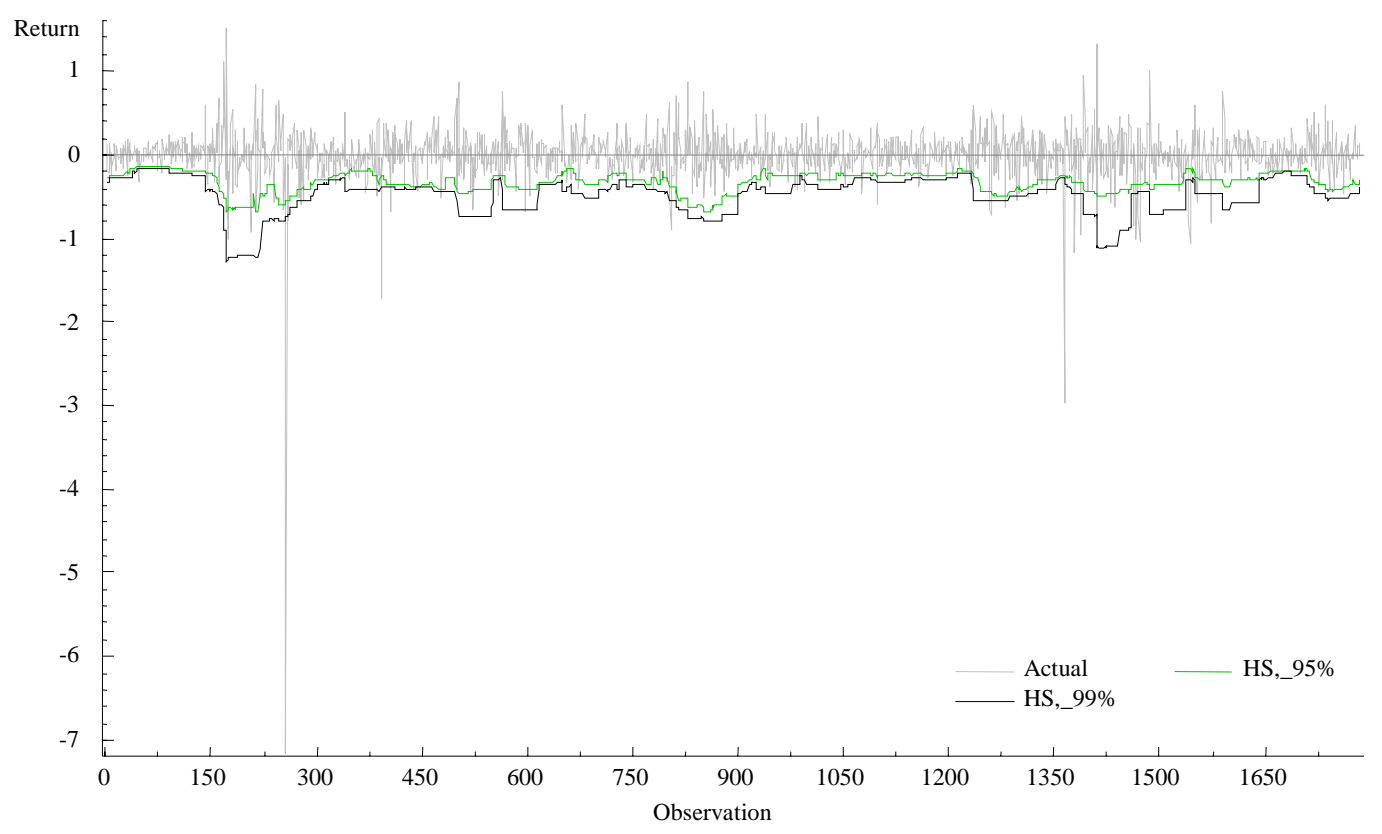

7a: 50 day window

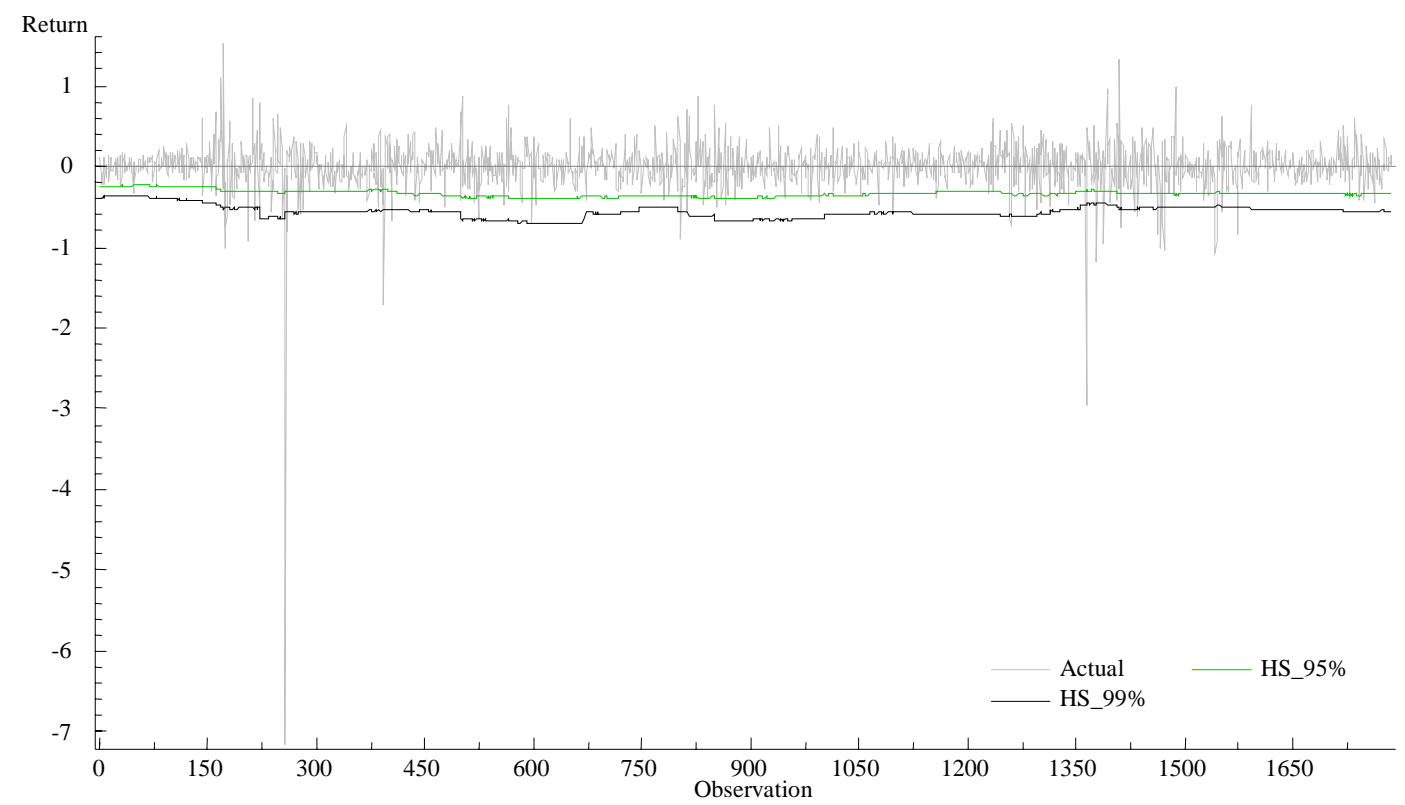

7b: 500 day window 
Tables 2a-2d: Evaluation statistics $-95 \%$ VaR

\begin{tabular}{ccccccccc}
\hline \hline & \multicolumn{2}{c}{50 days } & \multicolumn{2}{c}{ 125 days } & \multicolumn{2}{c}{ 250 days } & \multicolumn{2}{c}{500 days } \\
\cline { 2 - 8 } VCV & Average & Std. Dev. & Average & Std. Dev. & Average & Std. Dev. & Average & Std. Dev. \\
0.99 & -0.2863 & 0.1085 & 0.0915 & 0.2272 & 0.1128 & 0.2625 & 0.1533 & 0.3193 \\
0.97 & 0.0032 & 0.0711 & 0.0362 & 0.0852 & 0.0054 & 0.1225 & -0.0062 & 0.1490 \\
0.94 & 0.1066 & 0.1319 & 0.0213 & 0.1711 & -0.0262 & 0.1883 & -0.0409 & 0.1911 \\
OGar & 0.0569 & 0.2279 & 0.0179 & 0.3357 & -0.0278 & 0.3537 & -0.0695 & 0.3696 \\
HS & -0.0275 & 0.2163 & -0.0770 & 0.2161 & 0.1755 & 0.1717 & -0.1116 & 0.2388 \\
\hline \hline
\end{tabular}

Table 2a:Mean Relative Bias

\begin{tabular}{ccccccccc}
\hline \hline & \multicolumn{2}{c}{50 days } & \multicolumn{2}{c}{ 125 days } & \multicolumn{2}{c}{ 250 days } & \multicolumn{2}{c}{ 500 days } \\
\cline { 2 - 8 } VCV & Average & Std. Dev. & Average & Std. Dev. & Average & Std. Dev. & Average & Std. Dev. \\
0.99 & 0.2916 & 0.0539 & 0.2449 & 0.1766 & 0.2857 & 0.1402 & 0.3541 & 0.1640 \\
0.97 & 0.0712 & 0.0165 & 0.1554 & 0.0416 & 0.1485 & 0.0524 & 0.1989 & 0.0925 \\
0.94 & 0.1696 & 0.0629 & 0.1724 & 0.0648 & 0.1900 & 0.0726 & 0.1954 & 0.0767 \\
OGar & 0.2348 & 0.3092 & 0.3361 & 0.5075 & 0.3547 & 0.5405 & 0.3759 & 0.5223 \\
HS & 0.2180 & 0.0922 & 0.2294 & 0.0936 & 0.2455 & 0.0554 & 0.2634 & 0.0113 \\
\hline \hline
\end{tabular}

Table 2b:Root Mean Squared Relative Bias

\begin{tabular}{ccccccccc}
\hline \hline & \multicolumn{2}{c}{ 50 days } & \multicolumn{2}{c}{ 125 days } & \multicolumn{2}{c}{ 250 days } & \multicolumn{2}{c}{ 500 days } \\
\cline { 2 - 9 } VCV & Average & Std. Dev. & Average & Std. Dev. & Average & Std. Dev. & Average & Std. Dev. \\
0.99 & 0.1148 & 0.2118 & 0.0431 & 0.2032 & 0.0386 & 0.1928 & 0.0358 & 0.1859 \\
0.97 & 0.0610 & 0.2395 & 0.0622 & 0.2415 & 0.0420 & 0.2006 & 0.0375 & 0.1901 \\
0.94 & 0.0470 & 0.2118 & 0.0392 & 0.1941 & 0.0392 & 0.1941 & 0.0392 & 0.1941 \\
OGar & 0.0448 & 0.2069 & 0.0336 & 0.1802 & 0.0381 & 0.1914 & 0.0370 & 0.1887 \\
HS & 0.0711 & 0.2571 & 0.0560 & 0.2300 & 0.0532 & 0.2245 & 0.5655 & 0.2310 \\
\hline \hline
\end{tabular}

Table 2c:Binary Loss Function

\begin{tabular}{ccccccccc}
\hline & \multicolumn{2}{c}{50 days } & \multicolumn{2}{c}{ 125 days } & \multicolumn{2}{c}{ 250 days } & \multicolumn{2}{c}{ 500 days } \\
\cline { 2 - 8 } VCV & Average & Std. Dev. & Average & Std. Dev. & Average & Std. Dev. & Average & Std. Dev. \\
0.99 & 0.2135 & 1.9926 & 0.1337 & 1.7680 & 0.1236 & 1.6368 & 0.1153 & 1.5495 \\
0.97 & 0.1658 & 2.1238 & 0.1570 & 1.7938 & 0.1331 & 1.7928 & 0.1276 & 1.7928 \\
0.94 & 0.1593 & 2.4786 & 0.1488 & 2.1284 & 0.1416 & 2.1286 & 0.1416 & 2.1286 \\
OGar & 0.0967 & 0.7607 & 0.0728 & 0.5406 & 0.1488 & 2.4778 & 0.1488 & 2.4778 \\
HS & 0.1579 & 1.5266 & 0.1426 & 1.5178 & 0.1374 & 1.4689 & 0.1398 & 1.4384 \\
\hline \hline
\end{tabular}

Table 2d:Quadratic Loss Function 
Tables 3a-3d: Evaluation statistics $-99 \%$ VaR

\begin{tabular}{ccccccccc}
\hline \hline & \multicolumn{2}{c}{50 days } & \multicolumn{2}{c}{ 125 days } & \multicolumn{2}{c}{ 250 days } & \multicolumn{2}{c}{500 days } \\
\cline { 2 - 8 } VCV & Average & Std. Dev. & Average & Std. Dev. & Average & Std. Dev. & Average & Std. Dev. \\
0.99 & -0.2895 & 0.1116 & 0.0741 & 0.2219 & 0.0864 & 0.2559 & 0.1230 & 0.3034 \\
0.97 & -0.0012 & 0.0749 & -0.1043 & 0.1234 & 0.0004 & 0.1403 & 0.0496 & 0.1734 \\
0.94 & 0.1018 & 0.1337 & 0.0059 & 0.0023 & -0.0479 & 0.1885 & -0.0602 & 0.2043 \\
OGar & 0.0521 & 0.2267 & 0.0023 & 0.3314 & -0.0491 & 0.3518 & -0.1017 & 0.3326 \\
HS & -0.0054 & 0.2443 & 0.0019 & 0.2332 & 0.0281 & 0.2565 & 0.0164 & 0.2724 \\
\hline \hline
\end{tabular}

Table 3a:Mean Relative Bias

\begin{tabular}{ccccccccc}
\hline \hline & \multicolumn{2}{c}{50 days } & \multicolumn{2}{c}{ 125 days } & \multicolumn{2}{c}{ 250 days } & \multicolumn{2}{c}{500 days } \\
\cline { 2 - 9 } VCV & Average & Std. Dev. & Average & Std. Dev. & Average & Std. Dev. & Average & Std. Dev. \\
0.99 & 0.2952 & 0.0549 & 0.2339 & 0.1672 & 0.2700 & 0.1377 & 0.3272 & 0.1462 \\
0.97 & 0.0749 & 0.0170 & 0.1616 & 0.0409 & 0.1403 & 0.0464 & 0.1803 & 0.0707 \\
0.94 & 0.1680 & 0.0630 & 0.1725 & 0.0640 & 0.1945 & 0.0705 & 0.2129 & 0.0857 \\
OGar & 0.2325 & 0.3068 & 0.1725 & 0.4833 & 0.3551 & 0.5218 & 0.3468 & 0.5708 \\
HS & 0.2443 & 0.1008 & 0.2332 & 0.0831 & 0.2580 & 0.0852 & 0.2728 & 0.0950 \\
\hline \hline
\end{tabular}

Table 3b:Root Mean Squared Relative Bias

\begin{tabular}{ccccccccc}
\hline \hline & \multicolumn{2}{c}{50 days } & \multicolumn{2}{c}{ 125 days } & \multicolumn{2}{c}{250 days } & \multicolumn{2}{c}{ 500 days } \\
\cline { 2 - 9 } VCV & Average & Std. Dev. & Average & Std. Dev. & Average & Std. Dev. & Average & Std. Dev. \\
0.99 & 0.0627 & 0.1243 & 0.0207 & 0.1425 & 0.0179 & 0.1327 & 0.0190 & 0.1367 \\
0.97 & 0.0190 & 0.1367 & 0.0134 & 0.1152 & 0.0123 & 0.1103 & 0.0123 & 0.1103 \\
0.94 & 0.0106 & 0.1026 & 0.0084 & 0.0913 & 0.0084 & 0.0913 & 0.0084 & 0.0913 \\
OGar & 0.0112 & 0.1053 & 0.0067 & 0.0817 & 0.0078 & 0.0882 & 0.0078 & 0.0882 \\
HS & 0.0263 & 0.1601 & 0.0207 & 0.1425 & 0.0190 & 0.1367 & 0.0179 & 0.1327 \\
\hline \hline
\end{tabular}

Table 3c:Binary Loss Function

\begin{tabular}{ccccccccc}
\hline & \multicolumn{2}{c}{50 days } & \multicolumn{2}{c}{ 125 days } & \multicolumn{2}{c}{ 250 days } & \multicolumn{2}{c}{ 500 days } \\
\cline { 2 - 9 } VCV & Average & Std. Dev. & Average & Std. Dev. & Average & Std. Dev. & Average & Std. Dev. \\
0.99 & 0.1659 & 2.3013 & 0.1076 & 1.9655 & 0.0984 & 1.7724 & 0.0964 & 1.6477 \\
0.97 & 0.1164 & 2.9771 & 0.1176 & 1.9988 & 0.1045 & 2.0032 & 0.997 & 2.0033 \\
0.94 & 0.1129 & 3.0507 & 0.1082 & 2.5095 & 0.1067 & 2.5101 & 0.1067 & 2.5101 \\
OGar & 0.0432 & 0.8505 & 0.0293 & 0.5262 & 0.0260 & 0.4536 & 0.0261 & 0.4517 \\
HS & 0.0962 & 1.5635 & 0.0936 & 1.6505 & 0.0948 & 1.5820 & 0.0893 & 1.5211 \\
\hline \hline
\end{tabular}

Table 3d:Quadratic Loss Function 
Table 4: Decomposition of the Test of Conditional Coverage - 95\% VaR

\begin{tabular}{cccccccc}
\hline \hline & \multicolumn{3}{c}{50 days } & & \multicolumn{3}{c}{125 days } \\
\cline { 2 - 4 } \cline { 6 - 8 } & $\mathrm{LR}_{\mathrm{uc}}$ & $\mathrm{LR}_{\text {ind }}$ & $\mathrm{LR}_{\mathrm{cc}}$ & & $\mathrm{LR}_{\mathrm{uc}}$ & $\mathrm{LR}_{\mathrm{ind}}$ & $\mathrm{LR}_{\mathrm{cc}}$ \\
$\mathrm{VCV}$ & 0.3375 & $7.4285^{*}$ & $7.8623^{*}$ & & 1.8668 & $9.9624^{*}$ & $11.917^{*}$ \\
0.99 & $117.39^{*}$ & 2.1227 & $119.76^{*}$ & & $5.1701^{*}$ & $6.6285^{*}$ & $11.927^{*}$ \\
0.97 & $4.2871^{*}$ & $4.0434^{*}$ & $8.4566^{*}$ & & 2.1912 & $5.6059^{*}$ & $7.8841^{*}$ \\
0.94 & 0.3375 & 1.0217 & 1.4556 & & $4.7278^{*}$ & 1.6424 & $6.4502^{*}$ \\
OGar & 1.0549 & $4.5440^{*}$ & 5.6906 & & $11.384^{*}$ & $8.3522^{*}$ & $19.805^{*}$ \\
HS & $14.899^{*}$ & $10.112^{*}$ & $25.159^{*}$ & & 1.3013 & $8.3162^{*}$ & $9.7328^{*}$ \\
\hline \hline
\end{tabular}

\begin{tabular}{|c|c|c|c|c|c|c|}
\hline & \multicolumn{3}{|c|}{250 days } & \multicolumn{3}{|c|}{500 days } \\
\hline & $\mathrm{LR}_{\mathrm{uc}}$ & $\mathrm{LR}_{\text {ind }}$ & $\mathrm{LR}_{\mathrm{cc}}$ & $\mathrm{LR}_{\mathrm{uc}}$ & $\mathrm{LR}_{\text {ind }}$ & $\mathrm{LR}_{\mathrm{cc}}$ \\
\hline VCV & $5.2524^{*}$ & $5.4328 *$ & $10.764 *$ & $8.3362 *$ & $12.729 *$ & $21.138 *$ \\
\hline 0.99 & 2.5432 & $10.776^{*}$ & $13.405^{*}$ & $6.3924^{*}$ & $8.5243^{*}$ & 14.993* \\
\hline 0.97 & 3.7675 & $4.6306 *$ & $8.4804^{*}$ & 3.7675 & $4.6306^{*}$ & $8.4804^{*}$ \\
\hline 0.94 & $4.7278 *$ & 1.6424 & $6.4504^{*}$ & $4.7278^{*}$ & 1.6424 & $6.4502 *$ \\
\hline OGar & $5.8071 *$ & $5.7180 *$ & $11.603^{*}$ & $4.2330^{*}$ & 1.5040 & 5.8181 \\
\hline HS & 0.3755 & $7.9869 *$ & $8.4717^{*}$ & 1.5509 & $10.045^{*}$ & $11.712 *$ \\
\hline
\end{tabular}

* signifies LR test is significant at the $5 \%$ level.

Table 5: Decomposition of the Test of Conditional Coverage - 99\% VaR

\begin{tabular}{cccccccc}
\hline \hline & \multicolumn{3}{c}{50 days } & & \multicolumn{3}{c}{125 days } \\
\cline { 2 - 4 } \cline { 6 - 8 } VCV & $\mathrm{LR}_{\mathrm{uc}}$ & $\mathrm{LR}_{\text {ind }}$ & $\mathrm{LR}_{\mathrm{cc}}$ & & $\mathrm{LR}_{\mathrm{uc}}$ & $\mathrm{LR}_{\text {ind }}$ & $\mathrm{LR}_{\mathrm{cc}}$ \\
0.99 & $228.07^{*}$ & $6.9018^{*}$ & $11.892^{*}$ & & $15.826^{*}$ & $7.3480^{*}$ & $23.216^{*}$ \\
0.97 & $11.646^{*}$ & $4.8368^{*}$ & $234.53^{*}$ & & $37.179^{*}$ & $6.4033^{*}$ & $43.638^{*}$ \\
0.94 & 0.0720 & & & 1.9249 & $4.1873^{*}$ & $6.1393^{*}$ \\
OGar & 0.2493 & $5.5340^{*}$ & 0.5022 & & 0.4892 & 0.2542 & 0.7603 \\
HS & $33.156^{*}$ & $14.270^{*}$ & $47.479^{*}$ & & 15.1956 & $16.827^{*}$ & $19.036^{*}$ \\
\hline \hline
\end{tabular}

\begin{tabular}{|c|c|c|c|c|c|c|}
\hline & \multicolumn{3}{|c|}{250 days } & \multicolumn{3}{|c|}{500 days } \\
\hline & $\mathrm{LR}_{\mathrm{uc}}$ & $\mathrm{LR}_{\text {ind }}$ & $\mathrm{LR}_{\mathrm{cc}}$ & $\mathrm{LR}_{\mathrm{uc}}$ & $\mathrm{LR}_{\text {ind }}$ & $\mathrm{LR}_{\mathrm{cc}}$ \\
\hline VCV & $9.1564 *$ & $14.120^{*}$ & $23.313^{*}$ & $11.646 *$ & $17.844^{*}$ & $29.529 *$ \\
\hline 0.99 & $8.0062 *$ & $9.9460 *$ & $17.987 *$ & 3.2852 & $12.699 *$ & $16.013 *$ \\
\hline 0.97 & 0.9028 & $4.8197^{*}$ & 5.7472 & 0.9028 & $4.8200^{*}$ & 5.7472 \\
\hline 0.94 & 0.4892 & 0.2542 & 0.7603 & 0.4892 & 0.2542 & 0.7603 \\
\hline OGar & 0.9102 & 0.2213 & 1.1473 & 0.9102 & 0.2213 & 1.1473 \\
\hline HS & $11.646^{*}$ & $12.934^{*}$ & $24.618^{*}$ & $9.1564 *$ & $19.326 *$ & $28.519 *$ \\
\hline
\end{tabular}

* signifies LR test is significant at the 5\% level. 
Tables 6a-6d: Evaluation statistics $-95 \%$ VaR (Sample: July $1^{\text {st }} 1993-17^{\text {th }}$ December 1998 )

\begin{tabular}{ccccccccc}
\hline \hline & \multicolumn{2}{c}{50 days } & \multicolumn{2}{c}{ 125 days } & \multicolumn{2}{c}{ 250 days } & \multicolumn{2}{c}{500 days } \\
\cline { 2 - 8 } VCV & Average & Std. Dev. & Average & Std. Dev. & Average & Std. Dev. & Average & Std. Dev. \\
0.99 & -0.2903 & 0.0847 & 0.0852 & 0.1845 & 0.1404 & 0.2487 & 0.2101 & 0.2987 \\
0.97 & -0.0013 & 0.0612 & 0.0319 & 0.0703 & -0.0083 & 0.1034 & -0.0315 & 0.1256 \\
0.94 & 0.1046 & 0.1240 & 0.0286 & 0.1540 & -0.0292 & 0.1726 & -0.0539 & 0.1787 \\
OGar & 0.0567 & 0.1826 & -0.0006 & 0.2305 & -0.0591 & 0.2521 & -0.1142 & 0.2448 \\
HS & -0.0101 & 0.1983 & -0.0479 & 0.1865 & -0.0686 & 0.1900 & -0.0816 & 0.2021 \\
\hline \hline
\end{tabular}

Table 6a:Mean Relative Bias

\begin{tabular}{ccccccccc}
\hline \hline & \multicolumn{2}{c}{50 days } & \multicolumn{2}{c}{ 125 days } & \multicolumn{2}{c}{250 days } & \multicolumn{2}{c}{500 days } \\
\cline { 2 - 8 } VCV & Average & Std. Dev. & Average & Std. Dev. & Average & Std. Dev. & Average & Std. Dev. \\
0.99 & 0.2934 & 0.0271 & 0.2032 & 0.1460 & 0.2855 & 0.1468 & 0.3651 & 0.1715 \\
0.97 & 0.0612 & 0.0092 & 0.0771 & 0.0090 & 0.1037 & 0.0154 & 0.1294 & 0.0189 \\
0.94 & 0.1622 & 0.0552 & 0.1566 & 0.0489 & 0.1750 & 0.0542 & 0.1866 & 0.0553 \\
OGar & 0.1912 & 0.1474 & 0.2305 & 0.1759 & 0.2589 & 0.2185 & 0.2701 & 0.1468 \\
HS & 0.1985 & 0.0632 & 0.1925 & 0.0601 & 0.2019 & 0.0553 & 0.2179 & 0.0675 \\
\hline \hline
\end{tabular}

Table 6b:Root Mean Squared Relative Bias

\begin{tabular}{ccccccccc}
\hline \hline & \multicolumn{2}{c}{ 50 days } & \multicolumn{2}{c}{ 125 days } & \multicolumn{2}{c}{ 250 days } & \multicolumn{2}{c}{ 500 days } \\
\cline { 2 - 9 } VCV & Average & Std. Dev. & Average & Std. Dev. & Average & Std. Dev. & Average & Std. Dev. \\
0.99 & 0.1192 & 0.2147 & 0.0449 & 0.2071 & 0.0379 & 0.1909 & 0.0330 & 0.1786 \\
0.97 & 0.0624 & 0.2420 & 0.0638 & 0.2445 & 0.0428 & 0.2024 & 0.0379 & 0.1909 \\
0.94 & 0.0491 & 0.2161 & 0.0414 & 0.1992 & 0.0414 & 0.1992 & 0.0414 & 0.1992 \\
OGar & 0.0400 & 0.1960 & 0.0372 & 0.1892 & 0.0407 & 0.1976 & 0.0449 & 0.2071 \\
HS & 0.0729 & 0.2601 & 0.0561 & 0.2302 & 0.0519 & 0.2219 & 0.0540 & 0.2261 \\
\hline \hline
\end{tabular}

Table 6c:Binary Loss Function

\begin{tabular}{ccccccccc}
\hline & \multicolumn{2}{c}{50 days } & \multicolumn{2}{c}{ 125 days } & \multicolumn{2}{c}{ 250 days } & \multicolumn{2}{c}{ 500 days } \\
\cline { 2 - 8 } VCV & Average & Std. Dev. & Average & Std. Dev. & Average & Std. Dev. & Average & Std. Dev. \\
0.99 & 0.1842 & 0.6086 & 0.1000 & 0.5830 & 0.0902 & 0.5695 & 0.0798 & 0.5301 \\
0.97 & 0.1236 & 0.6145 & 0.1231 & 0.5947 & 0.0978 & 0.5888 & 0.0916 & 0.5851 \\
0.94 & 0.1107 & 0.6946 & 0.1020 & 0.6331 & 0.0997 & 0.6340 & 0.0998 & 0.6341 \\
OGar & 0.0958 & 0.8254 & 0.0832 & 0.5938 & 0.0834 & 0.5512 & 0.0894 & 0.5548 \\
HS & 0.1274 & 0.5417 & 0.1097 & 0.5441 & 0.1054 & 0.5375 & 0.1073 & 0.5328 \\
\hline \hline
\end{tabular}

Table 6d:Quadratic Loss Function 
Tables 7a-7d: Evaluation statistics $-99 \%$ VaR (Sample: July $1^{\text {st }} 1993-17^{\text {th }}$ December 1998$)$

\begin{tabular}{ccccccccc}
\hline \hline & \multicolumn{2}{c}{50 days } & \multicolumn{2}{c}{ 125 days } & \multicolumn{2}{c}{ 250 days } & \multicolumn{2}{c}{500 days } \\
\cline { 2 - 8 } VCV & 0.1354 & 0.0862 & 0.0687 & 0.1781 & 0.1120 & 0.2418 & 0.1782 & 0.2899 \\
0.99 & -0.2934 & 0.0442 & -0.1105 & 0.0884 & -0.0002 & 0.1117 & 0.0438 & 0.1492 \\
0.97 & -0.0054 & 0.0652 & 0.0173 & 0.0761 & -0.0314 & 0.1088 & -0.0557 & 0.1284 \\
0.94 & 0.1001 & 0.1266 & 0.0147 & 0.1589 & -0.0512 & 0.1766 & -0.0775 & 0.1790 \\
OGar & 0.0520 & 0.1812 & -0.0146 & 0.2311 & -0.0806 & 0.2524 & -0.1357 & 0.2453 \\
HS & 0.0113 & 0.2186 & 0.0244 & 0.2142 & 0.0513 & 0.2408 & 0.0469 & 0.2484 \\
\hline \hline
\end{tabular}

Table 7a:Mean Relative Bias

\begin{tabular}{ccccccccc}
\hline \hline & \multicolumn{2}{c}{50 days } & \multicolumn{2}{c}{ 125 days } & \multicolumn{2}{c}{ 250 days } & \multicolumn{2}{c}{ 500 days } \\
\cline { 2 - 8 } VCV & Average & Std. Dev. & Average & Std. Dev. & Average & Std. Dev. & Average & Std. Dev. \\
0.99 & 0.2967 & 0.0268 & 0.1909 & 0.1411 & 0.2664 & 0.1451 & 0.3402 & 0.1538 \\
0.97 & 0.0655 & 0.0273 & 0.1415 & 0.0249 & 0.1117 & 0.0275 & 0.1554 & 0.0475 \\
0.94 & 0.1613 & 0.0549 & 0.0780 & 0.0099 & 0.1132 & 0.0159 & 0.1399 & 0.0196 \\
OGar & 0.1885 & 0.1468 & 0.2315 & 0.1760 & 0.2648 & 0.2095 & 0.2802 & 0.1430 \\
HS & 0.2188 & 0.0714 & 0.2155 & 0.0712 & 0.2461 & 0.0664 & 0.2527 & 0.0752 \\
\hline \hline
\end{tabular}

Table 7b:Root Mean Squared Relative Bias

\begin{tabular}{ccccccccc}
\hline \hline & \multicolumn{2}{c}{ 50 days } & \multicolumn{2}{c}{ 125 days } & \multicolumn{2}{c}{250 days } & \multicolumn{2}{c}{ 500 days } \\
\cline { 2 - 8 } VCV & Average & Std. Dev. & Average & Std. Dev. & Average & Std. Dev. & Average & Std. Dev. \\
0.99 & 0.0652 & 0.1287 & 0.0217 & 0.1459 & 0.0161 & 0.1260 & 0.0168 & 0.1287 \\
0.97 & 0.0210 & 0.1436 & 0.0140 & 0.1176 & 0.0133 & 0.1147 & 0.0133 & 0.1147 \\
0.94 & 0.0112 & 0.1054 & 0.0084 & 0.0914 & 0.0084 & 0.0914 & 0.0084 & 0.0914 \\
OGar & 0.0105 & 0.1021 & 0.0070 & 0.0835 & 0.0077 & 0.0875 & 0.0084 & 0.0914 \\
HS & 0.0273 & 0.1632 & 0.0224 & 0.1482 & 0.0196 & 0.1388 & 0.0161 & 0.1260 \\
\hline \hline
\end{tabular}

Table 7c:Binary Loss Function

\begin{tabular}{ccccccccc}
\hline & \multicolumn{2}{c}{50 days } & \multicolumn{2}{c}{ 125 days } & \multicolumn{2}{c}{ 250 days } & \multicolumn{2}{c}{ 500 days } \\
\cline { 2 - 8 } VCV & Average & Std. Dev. & Average & Std. Dev. & Average & Std. Dev. & Average & Std. Dev. \\
0.99 & 0.1252 & 0.6284 & 0.0698 & 0.6060 & 0.0596 & 0.5880 & 0.0594 & 0.5495 \\
0.97 & 0.0692 & 0.6654 & 0.0792 & 0.6032 & 0.0656 & 0.6172 & 0.0596 & 0.6109 \\
0.94 & 0.0493 & 0.7162 & 0.0445 & 0.7127 & 0.0445 & 0.7128 & 0.0445 & 0.7128 \\
OGar & 0.0486 & 0.9473 & 0.0333 & 0.5818 & 0.0282 & 0.4978 & 0.0298 & 0.4995 \\
HS & 0.0679 & 0.4890 & 0.0638 & 0.5190 & 0.0638 & 0.5384 & 0.0540 & 0.5037 \\
\hline \hline
\end{tabular}

Table 7d:Quadratic Loss Function 
Table 8: Decomposition of the Test of Conditional Coverage - 95\% VaR (Sample: July $1^{\text {st }} 1993-17^{\text {th }}$ December 1998 )

\begin{tabular}{|c|c|c|c|c|c|c|}
\hline & \multicolumn{3}{|c|}{50 days } & \multicolumn{3}{|c|}{125 days } \\
\hline & $\mathrm{LR}_{\mathrm{uc}}$ & $\mathrm{LR}_{\text {ind }}$ & $\mathrm{LR}_{\mathrm{cc}}$ & $\mathrm{LR}_{\mathrm{uc}}$ & $\mathrm{LR}_{\text {ind }}$ & $\mathrm{LR}_{\mathrm{cc}}$ \\
\hline VCV & 0.0789 & $10.052 *$ & $10.130 *$ & 0.8136 & $9.6029 *$ & $10.416 *$ \\
\hline 0.99 & $105.40 *$ & 3.5011 & $108.90^{*}$ & $5.2892 *$ & $7.8582 *$ & $13.147^{*}$ \\
\hline 0.97 & $4.3020 *$ & $6.6511 *$ & $10.953^{*}$ & 1.0568 & $7.4115^{*}$ & $8.4682 *$ \\
\hline 0.94 & 0.0251 & 1.7663 & 1.7914 & 2.3670 & 2.2922 & 4.6592 \\
\hline OGar & 3.2321 & $9.9177 *$ & $13.150 *$ & $5.4060 *$ & $8.7361 *$ & $14.142 *$ \\
\hline $\mathrm{HS}$ & $13.915^{*}$ & $14.987 *$ & $28.902^{*}$ & 1.0768 & $10.171 *$ & $11.248^{*}$ \\
\hline
\end{tabular}

\begin{tabular}{|c|c|c|c|c|c|c|}
\hline & \multicolumn{3}{|c|}{250 days } & \multicolumn{3}{|c|}{500 days } \\
\hline & $\mathrm{LR}_{\mathrm{uc}}$ & $\mathrm{LR}_{\text {ind }}$ & $\mathrm{LR}_{\mathrm{cc}}$ & $\mathrm{LR}_{\mathrm{uc}}$ & $\mathrm{LR}_{\text {ind }}$ & $\mathrm{LR}_{\mathrm{cc}}$ \\
\hline VCV & $4.8055^{*}$ & $5.6367 *$ & $10.442 *$ & $9.8589 *$ & $11.600^{*}$ & $21.460 *$ \\
\hline 0.99 & 1.6434 & $10.989 *$ & $12.632 *$ & $4.8055^{*}$ & $8.3131 *$ & $13.119 *$ \\
\hline 0.97 & 1.9878 & $6.0581^{*}$ & $8.0459 *$ & 1.9878 & $6.0581^{*}$ & $8.0459 *$ \\
\hline 0.94 & 2.3670 & 2.2922 & 4.6592 & 2.3670 & 2.2922 & 4.6592 \\
\hline OGar & 2.7816 & $6.7583^{*}$ & $9.5400 *$ & 0.8135 & 1.4411 & 2.2547 \\
\hline HS & 0.1064 & $5.8103 *$ & 5.9166 & 0.4680 & $9.0839 *$ & $9.5519 *$ \\
\hline
\end{tabular}

* signifies LR test is significant at the $5 \%$ level.

Table 9: Decomposition of the Test of Conditional Coverage - 99\% VaR (Sample: July $1^{\text {st }} 1993-17^{\text {th }}$ December 1998)

\begin{tabular}{|c|c|c|c|c|c|c|}
\hline \multirow[b]{3}{*}{ VCV } & \multicolumn{3}{|c|}{50 days } & \multicolumn{3}{|c|}{125 days } \\
\hline & $\mathrm{LR}_{\mathrm{uc}}$ & $\mathrm{LR}_{\text {ind }}$ & $\mathrm{LR}_{\mathrm{cc}}$ & $\mathrm{LR}_{\mathrm{uc}}$ & $\mathrm{LR}_{\text {ind }}$ & $\mathrm{LR}_{\mathrm{cc}}$ \\
\hline & $5.5759 *$ & $7.4370 *$ & $13.013 *$ & $14.864 *$ & $8.3614^{*}$ & $23.225 *$ \\
\hline 0.99 & $195.77 *$ & $9.0971 *$ & $204.87 *$ & $33.631 *$ & $7.5757 *$ & $41.207 *$ \\
\hline 0.97 & $13.321 *$ & $5.0123 *$ & $18.333^{*}$ & 2.0743 & $4.7294 *$ & $6.8037 *$ \\
\hline 0.94 & 0.2063 & 0.3631 & 0.5694 & 0.3824 & 0.2037 & 0.5861 \\
\hline OGar & 0.0381 & $6.9542 *$ & $6.9923^{*}$ & 1.4354 & $16.787 *$ & $18.223^{*}$ \\
\hline HS & $29.432 *$ & $16.460 *$ & $45.893 *$ & $16.474^{*}$ & $16.825^{*}$ & $33.299 *$ \\
\hline
\end{tabular}

\begin{tabular}{|c|c|c|c|c|c|c|}
\hline & \multicolumn{3}{|c|}{250 days } & \multicolumn{3}{|c|}{500 days } \\
\hline & $\mathrm{LR}_{\mathrm{uc}}$ & $\mathrm{LR}_{\text {ind }}$ & $\mathrm{LR}_{\mathrm{cc}}$ & $\mathrm{LR}_{\mathrm{uc}}$ & $\mathrm{LR}_{\text {ind }}$ & $\mathrm{LR}_{\mathrm{cc}}$ \\
\hline $\mathrm{VCV}$ & $4.5639 *$ & $13.007 *$ & $17.571 *$ & $5.5759 *$ & $17.902 *$ & $23.478 *$ \\
\hline 0.99 & $7.8511 *$ & $11.041 *$ & $18.892 *$ & 2.8089 & $14.510^{*}$ & $17.319 *$ \\
\hline 0.97 & 1.4412 & $5.1123 *$ & $6.5534^{*}$ & 1.4412 & $5.1123 *$ & $6.5534^{*}$ \\
\hline 0.94 & 0.3824 & 0.2037 & 0.5861 & 0.3824 & 0.2037 & 0.5861 \\
\hline OGar & 0.8171 & 0.1710 & 0.9882 & 0.3824 & 0.2037 & 0.5861 \\
\hline HS & $10.440 *$ & $14.719 *$ & $25.159 *$ & $4.5639^{*}$ & $18.806^{*}$ & $23.370^{*}$ \\
\hline
\end{tabular}

* signifies LR test is significant at the $5 \%$ level. 